\title{
Hydromechanical modeling of pulse tests that measure both fluid pressure and fracture-normal displacement at the Coaraze Laboratory site, France
}

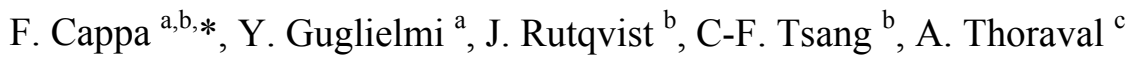 \\ ${ }^{a}$ Géosciences Azur, CNRS-UNSA-IRD-UPMC, 06560 Sophia-Antipolis, France \\ ${ }^{\mathrm{b}}$ Lawrence Berkeley National Laboratory, Earth Sciences Division, Berkeley, CA 94 720, USA \\ ${ }^{\mathrm{c}}$ INERIS, Ecole National Supérieure des Mines de Nancy, 54020 Nancy, France \\ * Corresponding author. Fax: (+33) 4.92.94.26.10 \\ E-mail address: cappa@geoazur.unice.fr (F. Cappa)
}

\begin{abstract}
In situ fracture mechanical deformation and fluid flow interactions are investigated through a series of hydraulic pulse injection tests, using specialized borehole equipment that can simultaneously measure fluid pressure and fracture displacements. The tests were conducted in two horizontal boreholes spaced one meter apart vertically and intersecting a near-vertical highly permeable fault located within a shallow fractured carbonate rock. The field data were evaluated by conducting a series of coupled hydromechanical numerical analyses, using both distinct-element and finite-element modeling techniques and both two- and three-dimensional model representations that can incorporate various complexities in fracture network geometry.
\end{abstract} One unique feature of these pulse injection experiments is that the entire test cycle, both the initial pressure increase and subsequent pressure fall-off, is carefully monitored and used for the evaluation of the in situ hydromechanical behavior. Field test data are evaluated by plotting fracture normal displacement as a function of fluid pressure, measured at the same borehole. The resulting normal displacement-versus-pressure curves show a characteristic loop, in which the paths for loading (pressure increase) and unloading (pressure decrease) are different. By matching this characteristic loop behavior, the fracture normal stiffness and an equivalent stiffness (Young's modulus) of the surrounding rock mass can be back-calculated. Evaluation of the field tests by coupled numerical hydromechanical modeling shows that initial fracture hydraulic aperture and normal stiffness vary by a factor of 2 to 3 for the two 
monitoring points within the same fracture plane. Moreover, the analyses show that hydraulic aperture and the normal stiffness of the pulse-tested fracture, the stiffness of surrounding rock matrix, and the properties and geometry of the surrounding fracture network significantly affect coupled hydromechanical responses during the pulse injection test. More specifically, the pressure-increase path of the normal displacement-versus-pressure curve is highly dependent on the hydromechanical parameters of the tested fracture and the stiffness of the matrix near the injection point, whereas the pressure-decrease path is highly influenced by mechanical processes within a larger portion of the surrounding fractured rock.

Key words: numerical modeling; pulse tests; fractures network; hydromechanical coupling; simultaneous pressure and fracture-normal displacement measurements; distinct element method; finite element method

\section{Introduction}

A particularly important feature in the interaction between mechanical deformation and fluid flow in fractured rock is its heterogeneity, both at the scale of the single fracture and the entire fracture network. However, complete and accurate description of the hydromechanical interactions within fractured rock is often difficult, largely because of the complexity of the fracture-network geometry and the heterogeneity in both fracture and rock-matrix hydromechanical properties.

The hydromechanical behavior of fractured rock has been extensively studied through laboratory experiments on single fractures [1-18], field testing [5,19-31], and numerical simulations [32-42]. Most of the field studies have been conducted at great depth in fractured hard rock, in which the permeability of the rock matrix is generally low and fractures act as dominating fluid conducting pathways. In the study presented in this paper, the main 
mechanisms for coupled hydromechanical processes are the mechanical deformation and fluid flow occurring within the fracture network. Hydromechanical coupled effects within one fracture depend not only on its hydraulic and mechanical properties, but also on the hydraulic and mechanical connections with other fractures, the orientation and magnitude of effective stresses applied to fracture walls, and general orientation (dip).

In a few previous studies, hydraulic well-testing has been applied to investigate in situ coupled hydromechanical effects in fractured rock $[19,33]$. Those studies indicate that hydraulic field tests can provide a good estimate for the hydromechanical properties of fractures. In tight, hard rock, single-borehole hydraulic pulse injections have been applied to determine hydraulic properties of rock fractures, including permeability and storativity $[34,36,38]$. Using specialized equipment for short duration pulses, this method has been proven to be useful for measuring hydraulic properties in fractures located at several hundred meters depth, with hydraulic aperture values as small as a few microns $[34,36]$.

Conventionally, the interpretations of a pulse test are based on matching the field results to type curves of pressure change with time, assuming either uniform linear, radial, or spherical flow, but without consideration of coupled hydromechanical mechanisms [45-50]. Because of the complex flow paths and fluid-flow-induced deformations in a fracture network, such simple assumptions about flow geometry and the role of hydromechanical coupling may not be valid. Coupled hydromechanical modeling has shown that the deformation of a fracture during a pulse-injection test can induce misinterpretations, leading to a significant error in the determination of fracture permeability and storativity [34]. To improve accuracy in estimating the hydromechanical properties of fractures, Rutqvist et al. [37] recommended combining hydraulic field tests and fracture-mechanical-normal-displacement measurements. Mechanical measurements of transient aperture change during a pulse injection test can provide a 
substantially improved estimate of fracture storativity, which implies that fracture permeability can be determined more accurately from the pressure transient test. Nevertheless, field tests on single fractures or a fracture network that measure simultaneously both hydraulic and mechanical responses are rare [21,23,27-31].

The coupled hydromechanical behavior of fractured rock has been studied in rock mechanics over the past 30 years, primarily in research programs associated with geological disposal of nuclear waste [51]. These research programs are concerned with flow in fractures at great depths, under high stresses and with a relatively small hydraulic aperture and high stiffness. Fracture hydromechanical behavior under such conditions has been studied in several underground research laboratories. By contrast in the research that is the subject of this paper, hydraulic-pulse-test and hydromechanical measurements are carried out in a shallow fractured rock unit, the Coaraze Laboratory site located in southern France. The Coaraze medium-scale field experimental and modeling project [28] aims at understanding coupled groundwater and mechanical processes in complex, shallow, fractured and porous rock, in which fractures are highly permeable and well connected. This is an intermediate scale test site $(30 \mathrm{~m} \times 30 \mathrm{~m} \times$ $15 \mathrm{~m})$ where experimental conditions are relatively well controlled. Experiments conducted on that site explore mechanisms at a scale between laboratory and regional reservoir.

In this study, we combine simultaneous in situ measurements of fluid pressure and fracturenormal displacements during pulse-injection testing. A series of seventy pulse tests are conducted in two subhorizontal boreholes intersecting a near-vertical fracture within the Coaraze Laboratory site. Fracture hydromechanical responses (fluid pressure and normal displacement) are simultaneously monitored at two measuring points spaced about $1 \mathrm{~m}$ apart within the plane of the vertical fracture. 
In this paper, we first present the experimental set up and field test results, follwed by coupled hydromechanical modeling of a pulse test using two approaches: (1) a distinct-element fracture network model and (2) a finite-element model of the pulse-tested fracture embedded in an equivalent poro-elastic media. In the two kinds of numerical analysis, the observed normal displacement-versus-pressure responses are matched to back-calculate in situ fracture hydraulic aperture and normal stiffness. We subsequently evaluate, in a sensitivity study, the influence of several key parameters on the normal displacement-versus-pressure responses, including various fracture and rock-matrix hydraulic and mechanical properties, as well as fracture-network geometry.

\section{Field Hydromechanical Experiments}

\subsection{Test Site}

Field experiments were conducted at the Coaraze Laboratory site in France [28]. The site is a small fractured rock reservoir $(30 \mathrm{~m} \times 30 \mathrm{~m})$ in a surface outcrop made up of a $15 \mathrm{~m}$ thick pile of fractured limestone (Fig. 1a). The hydraulic boundaries of the reservoir are well constrained, with impervious layers at bottom and top, an impervious fault located downstream toward the southwest, and an exposed rock slope surface sealed by semi-permeable grout to a height of about $10 \mathrm{~m}$. Upstream, towards the northeast, a permeable fault allows water to continuously flow into the reservoir. The rock mass is naturally drained by a spring located in the southwest corner. For these experimental studies, the spring was artificially closed with a water gate that enabled us to control the piezometric level in the reservoir (by opening or closing of the gate). Thus, when the water gate is closed, no more discharge occurs at the spring, and the pressure increases and stabilizes up to $10 \mathrm{~m}$ above the water gate. When the water gate is opened, water stored in the reservoir flows out. 
A three-dimensional deterministic model of the discontinuity network geometry was obtained from surface and boring scan-line data (Fig. 1b). The reservoir network is made up of 26 discontinuities, forming three sets (Fig. 1a and 1b):

- Three faults with a N50 to N70 trend, a dip angle of $70^{\circ}$ to $90^{\circ}$ towards the NW $\left(\mathrm{F}_{11}\right.$, $F_{12}$ and $\left.F_{13}\right)$, and with a $2-3 \mathrm{~m}$ spacing;

- Eleven faults with a N120 to N140 trend, a dip angle of $75^{\circ}$ to $90^{\circ}$ towards the NE $\left(\mathrm{F}_{1}\right.$ to $\mathrm{F}_{10}$ and $\mathrm{F}_{14}$ ), and with a $2 \mathrm{~m}$ spacing;

- Twelve bedding planes with a N40 trend, a dip angle of $45^{\circ}$ towards the $\mathrm{SE}\left(\mathrm{S}_{1}\right.$ to $\left.\mathrm{S}_{12}\right)$, and with a 0.5 to $1 \mathrm{~m}$ spacing.

\subsection{Hydromechanical Behavior of the Fractured Rock Mass}

Using various hydraulic field tests, including measurement during opening and closure of the water gate, Cappa et al. [28] and Guglielmi and Murdy [52] investigated the overall fluid flow and hydromechanical behavior in the reservoir. Based on the fluid flow pattern and the time evolution of fluid flow and pressure responses, they found that the hydraulic responses at the site are governed by dual-permeability behavior. Directly after opening or closing the water gate, transient flow occurs only in the highly permeable faults $\left(0.57 \times 10^{-4}<\mathrm{K}_{\mathrm{F}}\right.$ (fault permeability) $<1.9 \times 10^{-4} \mathrm{~m} / \mathrm{s}$ ), and later, when a steady-state flow is reached in faults, water flows from faults to low-permeable bedding planes $\left(0.9 \times 10^{-6}<\mathrm{K}_{\mathrm{BP}}\right.$ (bedding plane permeability) $<7.6 \times 10^{-6} \mathrm{~m} / \mathrm{s}$ ). The rock matrix between major faults and bedding planes is practically impervious, whereas connectivity between discontinuities (major faults and bedding planes) is high. Simultaneous measurements of pressure and fracture-normal displacement indicate a direct hydromechanical coupling in the highly permeable faults, where a pressure increase is directly accompanied by fault opening. No direct hydromechanical coupling occurs within the low-permeable zones, where deformation does 
not directly correlate with pressure increase. This means that mechanical deformation in the bedding planes and rock matrix is induced by the opening of adjacent highly permeable faults.

\subsection{Experimental Setup}

Two horizontal boreholes (HM1 and HM2 in Fig. 2), spaced $1 \mathrm{~m}$ vertically, were drilled normal to the $F_{12}$ near-vertical fault (Fig. 2). Each borehole stops $5 \mathrm{~cm}$ beyond the fault. In each borehole, the fault was isolated with an inflatable packer to create an $0.4 \mathrm{~m}$ long sealed section. In each sealed section, the measurement device consists of a fiber-optic fluid pressure and a fiber-optic normal displacement sensor fixed to the borehole walls by two anchors located on both sides of the fault. This device was specially adapted from the BOF-EX device developed by $\operatorname{RocTest-Telemac}{ }^{\circledR}[30,53]$. This borehole equipment is capable of simultaneously measuring change (with a high frequency $[120 \mathrm{~Hz}]$ and high accuracy) in fluid pressure $( \pm 1 \mathrm{kPa})$ and displacement normal to the fault walls $\left( \pm 1 \times 10^{-7} \mathrm{~m}\right)$ during a fast pulse testing.

Before performing the pulse-test series, the spring-gate is closed in order to saturate the fracture network with water. Before each pulse test, initial pressure values are $39 \mathrm{kPa}$ at HM1 and $27 \mathrm{kPa}$ at $\mathrm{HM} 2$. The section sealed by the packer is connected to a valve leading to an upstream volume that is used to perform a pressure pulse test. To conduct the pulse tests, the fluid pressure is first increased upstream of the valve to the required pressure-pulse magnitude by a volumetric water pump, allowing a pressure increase from 10 to $700 \mathrm{kPa}$. Thereafter, the pulse is initiated when the valve is opened to allow water to enter inside the sealed section. The pressure first increases in the packed-off section, and then the valve is closed. After closing the water-gate, the pressure starts to decrease as a result of fluid flow into the fault. In both HM1 and HM2, a series of 70 pulse tests were conducted at different pressure magnitudes ( $\Delta \mathrm{P}=9$ to $86 \mathrm{kPa})$, repeated at least three times each. 


\section{Hydromechanical Measurements}

Among the 70 pulse tests, results for a pulse test of magnitude equal to $86 \mathrm{kPa}$ applied to HM1 are presented as an example of typical results (Fig. 3). Indeed, repeated for different pulse pressure, all the tests display the same curve shape. Data were sampled at a rate of 120 measurements per second with filtering of the instrumental noise. Fiber optic sensors allow accurate measurements, with a high sampling rate, of all the pressure changes during a shortduration pulse [30]. Thus, compared to the classical pulse curves for which only the pressure decrease stage is measured with sufficient resolution, fiber optic sensing allows interpretable field data for both pulse-pressure increase and decrease stages.

For a test duration of 40 seconds, the initiation of pulse $(t=0$ in Fig. 3a) begins 15 seconds after the start of monitoring. At HM1, the pressure change displays a nonlinear oscillatory behavior, with pressure increasing from $39 \mathrm{kPa}$ to $125 \mathrm{kPa}$ in 3.5 seconds, and then decreasing to reach its initial value in 8 seconds (Fig. 3a). The normal displacement follows the pressure change, although the displacement is less oscillatory and more damped compared to pressure. Around the time of peak pressure, the magnitude of normal displacement in HM1 reaches a maximum of $1.9 \times 10^{-6} \mathrm{~m}$. The peak pressure at $\mathrm{HM} 2$ is lower than at $\mathrm{HM} 1(\Delta \mathrm{P}=$ $22 \mathrm{kPa}$ instead of $86 \mathrm{kPa}$ ) and is reached 1.5 seconds later. At HM2, the pressure decrease is slower than the one at HM1. Normal displacement change at HM2 follows the local pressure change at HM2, with the magnitude of displacement reaching a maximum of $0.45 \times 10^{-6} \mathrm{~m}$.

The same pulse test is presented in a diagram with normal displacement-versus-fluid pressure (Fig. 3b). Both at HM1 and HM2, the curves follow a loop-shaped evolution, along different paths for pressure increase and decrease stages. The loop-like behavior indicates that pressure and normal displacement return to the initial starting point at the end of the pulse. During the 
pressure pulse evolution, the loop is regular, but near the return to ambient pressure, the shape of the loop becomes oscillatory. The higher the pulse magnitude, the thicker the loop. Results clearly indicate a difference of "loop" slopes at HM1 and HM2 (thin dashed lines between the initial conditions and the pressure-peak, in Fig. 3b).

Figure $3 \mathrm{c}$ illustrates the repeatability of the loop-like behavior showing three loops of same pulse magnitude $(\Delta \mathrm{P}=86 \mathrm{kPa})$. The curves are superimposed by less than $1 \mathrm{kPa}$ standard deviation in pressure and a less than $2 \times 10^{-7} \mathrm{~m}$ standard deviation in displacement.

Figure 4 presents a plot of maximal normal displacement-versus-maximum pressure and best fit linear trend lines for the entire series of pulse tests. Data at HM1 and at HM2 follow two different linear trend lines, with an average linear slope of normal displacement-versus-fluid pressure data equal to $2.34 \times 10^{-8} \mathrm{~m} / \mathrm{kPa}$ at $\mathrm{HM} 1$ and $1.81 \times 10^{-8} \mathrm{~m} / \mathrm{kPa}$ at $\mathrm{HM} 2$. The inverse of these values corresponds to a first order analytical estimate of an apparent fracture normal stiffness trend of about $43 \mathrm{GPa} / \mathrm{m}$ and $55 \mathrm{GPa} / \mathrm{m}$, at $\mathrm{HM} 1$ and $\mathrm{HM} 2$, respectively. Field data around these trend lines are scattered by less than $10 \mathrm{kPa}$ standard deviation in pressure and a less than $2 \times 10^{-7} \mathrm{~m}$ standard deviation in displacement. However, a closer analysis shows that displacement data for HM1 and HM2 approximately coincide for pulse magnitudes below 40 $\mathrm{kPa}$, whereas above a pressure of $40 \mathrm{kPa}, \mathrm{HM} 1$ data tends upwards and HM2 data trends downwards (Fig. 4).

\section{Coupled Hydromechanical Modeling of a Pulse Test}

\subsection{Numerical Analysis Methods}

Two numerical modeling approaches were used to simulate the above-mentioned pulse test of $86 \mathrm{kPa}$ applied to HM1. These approaches account for heterogeneous hydromechanical 
interactions in a complex fracture network as well as fracture-matrix hydromechanical interactions. First, the finite element code ROCMAS [54-55] was applied to investigate the effects of leakage into the rock matrix on the hydromechanical response. This code is developed from the Biot's theory of consolidation [56] for analysis of thermo-hydromechanical processes in saturated-unsaturated fractured porous rock media. In ROCMAS, a few fractures embedded in a permeable rock matrix can be discretized with discontinuity model elements embedded in solid model elements. Second, the UDEC and 3DEC distinct element codes [57-59] were selected to investigate the effects of fracture network geometry on the hydromechanical response. These codes simulate the fluid flow and deformation coupled processes of discrete fractures embedded in an impervious rock matrix. Thus, both modeling approaches are well suited to investigate the hydromechanical behavior of a fracture and complement each other in our study.

In the numerical analyses conducted herein, discontinuities and the rock matrix are considered to be linear elastic. A modified form of the cubic law (1) governs fluid flow in fractures $[44,60]:$

$$
q=\frac{\left(b_{h i}+f \Delta U_{n}\right)^{3} w \rho g}{12 \mu} \Delta h
$$

where $\mathrm{q}$ is the flow rate, $\mathrm{b}_{\mathrm{hi}}$ is the initial hydraulic aperture at the initial effective stress, $f$ is a factor reflecting the influence of the roughness on the tortuosity of the flow, $\Delta U_{n}$ is the change in fracture normal displacement, $\mathrm{w}$ is the fracture width, $\rho$ is the fluid density, $\mathrm{g}$ is the gravitational acceleration, $\mu$ is the fluid dynamic viscosity, and $\Delta \mathrm{h}$ is the change in hydraulic head. Fracture deformations and hydraulic apertures are calculated as a function of the effective stresses, assuming a constant normal stiffness for fractures. The modeling procedure consists of three stages: 
- The first modeling stage consists of a code intercomparison to check the capabilities and correspondence of the numerical simulation models. In this application, a pulse test was simulated by two- and three-dimensional axisymmetric models of a single horizontal fracture-2DAxM 1 (Fig. 5a and 6) and 3DAxM (Fig. 7a).

- A series of two-dimensional analyses are then conducted, both with a number of axisymmetric models of the pressurized fracture embedded in an equivalent elastic media $-2 \mathrm{DAxM}_{1}$ to $2 \mathrm{DAxM}_{5}$ in Fig. $5 \mathrm{a}$ - and a model of a vertical cross section, CSM in Fig. 5b, which includes an explicit fracture network. These analyses were conducted to investigate the influence of mechanical and hydraulic boundary conditions, the unsaturated zone, fracture properties, and the leakage into the rock matrix and intersecting fractures.

- The pulse tests are then simulated within a small-scale, three-dimensional, discrete fracture model centred on the pressurized zone-3DFM in Fig. 7b. A sensitivity analysis is then conducted to investigate the effects of fractures and rock matrix hydromechanical parameters and the geometry of the fracture network.

\subsection{Geometry, Boundary Conditions, and Basic Assumptions}

Figures 5 to 8 present an overview of the geometry and boundary conditions of the respective models. Models $2 \mathrm{DAxM}_{1-5}$ and $3 \mathrm{DAxM}$ simulate axisymmetric behavior, whereas models CSM and 3DFM include near-field geometry with explicit faults and bedding planes embedded in the rock matrix. Table 1 summarizes the model geometries, the numerical codes, and parameters tested in the sensitivity study.

Model $2 \mathrm{DAxM}_{1}$ corresponds to a two-dimensional model $(10 \mathrm{~m} \times 10 \mathrm{~m})$ of a single fracture surrounded by a deformable rock mass. Figure 6 shows a close-up view of the finite element mesh assigned to ROCMAS model. The two-dimensional analysis can be executed either as a 
two-dimensional plane strain analysis or as an axisymmetric analysis in a vertical fracture, neglecting the gravity effects on fluid flow and mechanical deformation. All boundaries are considered to be impermeable. Initial in situ fluid pressure is $39 \mathrm{kPa}$. A constant stress is applied on the top and the right boundaries. Null vertical displacement is imposed at the bottom boundary, and, null horizontal displacement at the left boundary.

Models $2 \mathrm{DAxM}_{2}$ to $2 \mathrm{DAxM}_{5}$ correspond to axisymmetric models that account for different mechanical boundary conditions, different sizes, and one or two parallel fractures. These models are detailed in an axisymmetric analysis of the hydromechanical response of a fracture when subjected to a pulse test (see Section 5.2).

Model CSM is a two-dimensional model corresponding to a vertical cross section $(20 \mathrm{~m} \times 20$ m) that represents the complete reservoir geometry through the HM1 and HM2 measuring points. All boundaries are impermeable. The topographic surface is free to move, whereas no displacement normal to the boundary is imposed at other boundaries. In situ fluid pressure is set according to the natural hydrostatic pressure gradient in the rock mass. The unsaturated zone is accounted for by affecting a zero initial saturation for fractures portions above the water table. The in situ stress gradient is set according to the weight of the overlying rock.

Model 3DAxM is a three-dimensional axisymmetric model $(10 \mathrm{~m} \times 10 \mathrm{~m} \times 10 \mathrm{~m})$ of a single fracture surrounded by a deformable rock mass. In situ and boundary conditions are the same as the ones used in the two-dimensional axisymmetric analysis (e.g., Model 2DAxM 1 ).

Model 3DFM corresponds to a three-dimensional explicit representation of the fracture network, the case closest to reality. A discrete model of the field test around the injection zone is analyzed, taking into account three faults $\left(\mathrm{F}_{11}, \mathrm{~F}_{\mathrm{n}}, \mathrm{F}_{12}\right)$ and four bedding planes $\left(\mathrm{S}_{7}, \mathrm{~S}_{8}, \mathrm{~S}_{9}\right.$, $\mathrm{S}_{10}$ ) (Fig. 1 and $6 \mathrm{~b}$ ). The model corresponds to a cube with $6 \mathrm{~m}$ sides centred at HM1. In situ 
and boundary fluid pressures are set according to the natural hydrostatic pressure gradient in the rock mass (Fig. 6c). On the top boundary, a vertical stress corresponding to the weight of the overburden rock mass is applied, with displacements fixed at other boundaries. The left boundary on the diagonal section of the three-dimensional model (Fig. 6c) is chosen in accordance with the sensitivity study of the mechanical boundary effects conducted in the two-dimensional analysis (see Sections 5.2 and 5.3.1). An in situ stress gradient is set according to the rock weight (Fig. 6c). Figure 8 shows the three models (cases I to III) used in the 3DEC sensitivity study to address the importance of the geometry of the fracture network on the hydromechanical response (see Section 5.4.5).

Mechanical properties of the rock matrix and the hydromechanical properties of bedding planes (Tables 2 and 3) are taken from previous in situ and laboratory experiments [28]. Based on previous evaluations of fault hydraulic permeability, the initial apertures of the main faults are set to $1 \times 10^{-4} \mathrm{~m}$.

In each simulation with ROCMAS, UDEC, and 3DEC, the pulse test is simulated by imposing a time-dependent pressure pulse corresponding to the pulse-pressure evolution in the injection borehole (Fig. 3a). The time-dependent borehole pressure function was programmed into each code, using standard FORTRAN for ROCMAS and special "FISH" programming [54] for UDEC and 3DEC. Thus, a consistent set of input parameters were used for each modeling approach enabling a direct comparison of between the simulation results of each model.

\section{Modeling Results and Sensitivity Analysis}

\subsection{Numerical Capabilities and Correspondence of the Codes for a Simple Injection Case}


In this code intercomparison, model $2 \mathrm{DAxM}_{1}$ is used in a two-dimensional plane strain or axisymmetric analysis, and model $3 \mathrm{DAxM}$ is used in a three-dimensional axisymmetric analysis. Results are almost identical for the two codes (Fig. 9). In the two-dimensional plane strain analysis, calculated curves fit perfectly the pulse-pressure-increase stage (Fig. 9a). During the pulse-pressure-decrease stage, the normal displacement magnitude is underestimated. For each code, the best fit to measurements was obtained with the same fracture and rock matrix hydromechanical properties (Table 2), including a fracture normal stiffness of $40 \mathrm{GPa} / \mathrm{m}$. For the two- and three-dimensional axisymmetric models, the best-fit solution to field data was obtained with the two codes for a unique set of parameters (Table 2), a fracture normal stiffness of $8 \mathrm{GPa} / \mathrm{m}$, a Young's modulus of $60 \mathrm{GPa}$, and an initial fracture aperture of $1 \times 10^{-4} \mathrm{~m}$. The ROCMAS solution accurately reproduces the observed behavior with a correlation coefficient $\left(\mathrm{r}^{2}\right)$ of 0.97 (Fig. 9b), while the 3DEC solution presents a lower correlation coefficient $\left(\mathrm{r}^{2}=0.57\right)$ because of a discrepancy between predicted and observed data during the pulse-pressure-decrease stage. Results are sensitive to the differences in mesh discretization near the injection zone between the two codes. Different grid spacings produce slightly different pressure gradients near the injection point, which in turn induces a discrepancy in simulated displacement. These results show that the two modeling approaches yield almost identical results for the same set of input data, therefore providing a degree of confidence that the basic coupled hydromechanical process models are correct in each code, and that the two models for the injection experiment are correctly implemented.

\subsection{Two-Dimensional Plane Strain Analyses}

Two-dimensional plane strain analyses were conducted using the various simplified models, $2 \mathrm{DAxM}_{1}$ through $2 \mathrm{DAxM}_{5}$, as well as the full section model, CSM, shown in Fig. 5. Figure $10 \mathrm{a}$ and $\mathrm{b}$ present the best-match two-dimensional plane strain solutions for models $2 \mathrm{DAxM}_{1}$ 
and CSM, respectively. The UDEC and ROCMAS two-dimensional plane strain results are similar for the same fracture and rock-matrix hydromechanical parameters (Table 2). The key parameter for this solution is fracture normal stiffness, which is calibrated to a value of 40 $\mathrm{GPa} / \mathrm{m}$ when the Young's modulus of the matrix is set to $70 \mathrm{GPa}$. The simulated loop is thinner than the one observed in the field, and a good match was obtained only for the pulsepressure-increase stage (Fig. 10). During the pulse-pressure-decrease stage, the normal displacement magnitude is underestimated, identical to the magnitude obtained in the previous two-dimensional plane strain analysis. Figure 10a and $\mathrm{b}$ show that the solution of the simple model is close to the solution of the full two-dimensional section, and there are few mechanical boundary effects as long as the boundary is at least $5 \mathrm{~m}$ away from the pressurized fracture. The results in Figure $10 \mathrm{~b}$ indicate that the use of constant stress, $2 \mathrm{DAxM}_{1}$, or null displacement, $2 \mathrm{DAxM}_{2}$, boundaries at the top and right side of the model does not have a significant effect on the hydromechanical response (Fig. 10a). However, it is clear from Figure 10 that a two-dimensional plane strain analysis is incapable of reproducing the observed thickness of the displacement-versus-pressure loop. As will be explained in Section 5.3, the thickness of the loop is related to the pressure gradient near the well bore and in particular to the difference in near-well pressure gradient during the increasing and decreasing parts of the pressure pulse. A two-dimensional plane strain analysis is not capable of representing the dominant radial-fluid-flow behavior near the well bore and therefore the back-calculated stiffness of $40 \mathrm{GPa} / \mathrm{m}$ is not an accurate representation of the fracture normal stiffness in the field, where a dominant radial fluid flow is expected.

\subsection{Two-Dimensional Axisymmetric Analyses}

Figure 11 presents the best-fit solution for a two-dimensional axisymmetric analysis with the ROCMAS code. Whereas the two-dimensional plane strain analysis failed to reproduce 
observed pressure-versus-displacement behavior, the two-dimensional axisymmetric analysis can reproduce the observed behavior accurately (Fig. 11). The best-fit solution in Figure 11 was obtained with the ROCMAS code for a fracture normal stiffness of $8 \mathrm{GPa} / \mathrm{m}$, a Young's modulus of $60 \mathrm{GPa}$, an initial fracture aperture of $1 \times 10^{-4} \mathrm{~m}$, and an equivalent radius of influence of about $3.9 \mathrm{~m}$ (Table 4). The equivalent radius of influence is a constant fluid pressure boundary representing the effect of the constant pressure conditions at water table, located at $3.9 \mathrm{~m}$ above the injection point. This assumption is justified by the previous analysis, which doesn't show effects of the unsaturated zone on the hydromechanical response (see Section 5.2).

Figure 11 also presents radial profiles of fluid pressure and fracture aperture, which help to explain the cause of the measured and simulated loop behavior. In essence, the loop behavior occurs because the fracture hydromechanical response is a result of the distribution of fluid pressure within the fracture rather than the local fluid pressure at the well. Fracture opening measured at the well is not directly proportional to the well pressure, but is rather a result of the total force applied on the fracture surfaces from the distributed fluid pressure over a larger fracture surface area. During the pressure increasing part, the pressure gradient is very steep near the well, and as a result the fluid pressure is much higher at the well than a few meters into the fracture. During the pressure decreasing part, on the other hand, the pressure gradient is much smaller, and hence, the fluid pressure at the well is not as much higher than the fluid pressure a few meters into the fracture. For example, at two seconds, the well pressure is 60 $\mathrm{kPa}$, whereas the fluid pressure at 1 meter radius is about $12 \mathrm{kPa}$. At 6 seconds, the well pressure has decreased to about $35 \mathrm{kPa}$, whereas the fluid pressure at 1 meter radius is still as high as $15 \mathrm{kPa}$. At 6 seconds, the fracture opening at the well bore is slightly larger than at 2 seconds, reflecting the fracture opening being proportional to the fluid pressure at 1 meter 
radius rather than being proportional to the well pressure. Thus, hydromechanical behavior of the fracture during the pulse injection test can only be reproduced by a model that correctly accounts for the dominating radial flow behavior, including a steep pressure gradient near the well bore. This can be done with three-dimensional or two-dimensional axisymmetric models, but not with a two-dimensional plane strain model. The fact that the measured thickness of the loop can be reproduced by an axisymmetric model, but not by a two-dimensional plane strain model, confirms that the fluid flow in the field test is indeed approximately radial near the well.

\subsubsection{Mechanical Boundary Effects}

The influence of mechanical boundary conditions was examined with a suite of differently sized two-dimensional models (Fig. 5a). The effect of the outer boundaries becomes significant if they are closer than about $5 \mathrm{~m}$ from the pressurized fracture. A smaller sized (5 m by $7 \mathrm{~m}$ ) axisymmetric model was used to test the influence of mechanical boundary conditions closer to the pressurized fracture (models $2 \mathrm{DAxM}_{3}$ and $2 \mathrm{DAxM}_{4}$, Fig. 5a). Results show that when the boundary moves as close as $5 \mathrm{~m}$ from the pressurized fracture, mechanical boundary conditions have a significant influence, particularly on the thickness of the displacement-pressure curve (Fig. 12a). The full loop is thicker when the upper boundary is

free to move under a constant stress. A separate analysis showed that the impact of the mechanical boundary conditions at the lateral boundary is less significant.

\subsubsection{Effects of Radius of Influence}

In the field, the water table is located about $3.9 \mathrm{~m}$ above HM1, and other fractures intersect the pressurized fault at various distances from HM1. The composite effect of the water table and water leakage into intersecting fractures may work as a constant fluid pressure boundary. In the axisymmetric model, these conditions may be represented by a constant pressure 
boundary at a certain equivalent radius from the injection point. In this case, the effect of the equivalent fluid pressure radius is tested using the model $2 \mathrm{DAxM}_{1}$, by imposing a constant fluid pressure at various radii along the fracture. Figure $12 \mathrm{~b}$ shows that the effect of such a constant pressure boundary would become significant if it were located closer than about 3.9 $\mathrm{m}$ from the injection point. A short radius of influence tends to prevent fracture opening because the pressurized area is smaller, and thereby the total force exerted on the fracture walls is smaller. Also, if the radius is larger than $3 \mathrm{~m}$, the effect is only visible for the pulsepressure decreasing stage.

\subsubsection{Effects of Fracture Normal Stiffness and Elastic Effects of Rock Matrix}

The sensitivity to fracture normal stiffness and Young's modulus of the rock matrix is analyzed with model $2 \mathrm{DAxM}_{1}$. The effect of fracture normal stiffness is studied for a fixed Young's modulus of $60 \mathrm{GPa}$ (Fig. 12c), while the effect of the Young's modulus for the rock matrix is analyzed for a fixed fracture normal stiffness of $8 \mathrm{GPa} / \mathrm{m}$ (Fig. 12d). Results show that fracture hydromechanical response is sensitive to changes in both fracture normal stiffness and the Young's modulus of the surrounding rock mass. Moreover, results show that if the fracture normal stiffness is much larger than the stiffness of the rock matrix, no loop appears in the displacement-versus-pressure curve. When the Young's modulus increases, a loop-shaped evolution appears. The loop appears because of dominant radial-fluid-flow behavior near HM1, which provides a steep pressure gradient combined with a fracture opening restricted by the stiffness of the surrounding rock.

\subsubsection{Leakage into Matrix and Poro-Elastic Effects}

The effect of leakage from the main fracture into the surrounding rock matrix was analyzed with model $2 \mathrm{DAxM}_{1}$. Results show that there is no significant leakage into the rock matrix unless the matrix permeability is higher than $1 \times 10^{-15} \mathrm{~m}^{2}$ (Fig. 12e). For a very high matrix 
permeability of $1 \times 10^{-14}$ or $1 \times 10^{-13} \mathrm{~m}^{2}$, the fracture opening is smaller, because leakage into the rock matrix reduces the amount of fluid flowing, and thus the pressure increase along the fracture. A shorter penetration distance implies that the total force of the fluid pressure applied on the fracture wall would be smaller. However, the matrix permeability is not likely to be higher than $1 \times 10^{-15} \mathrm{~m}^{2}$, even if the permeability of the bedding planes and small-scale discontinuities were included. Thus, leakage into the rock matrix and associated poro-elastic effects do not appear to be significant for the fracture hydromechanical responses during these pulse injection tests.

\subsubsection{Effects of Adjacent Faults}

How adjacent faults impact the hydromechanical response of the pressurized fracture is simulated with an axisymmetric model that includes two parallel horizontal fractures (model $2 \mathrm{DAxM}_{5}$, Fig. 5a). Model dimension is $7 \mathrm{~m}$ by $5 \mathrm{~m}$ and roughly corresponds to the distance from HM1 to the free surface of the rock slope. Fracture spacing is $2.5 \mathrm{~m}$ and corresponds to the distance between $F_{11}$ and $F_{12}$ in the full section (Fig. 5b). For model $2 \mathrm{DAxM}_{5}$, the bestmatch parameters of Young's modulus and fracture normal stiffness are slightly different than for model $2 \mathrm{DAxM}_{1}$. The full loop-shaped evolution is reproduced when the model includes the two fractures with a fracture normal stiffness $\mathrm{k}_{\mathrm{n}}=12 \mathrm{GPa} / \mathrm{m}$ and Young's modulus $\mathrm{E}=60$ GPa (Fig. 12f). When including the adjacent faults, the rock mass becomes more compliant (compared to the otherwise intact rock) and as a result, an additional fracture opening is induced, especially during the fluid-pressure decrease stage. This additional deformation occurs because the adjacent fracture is compressed and thereby accommodates deformation in the pressurized fracture deformation.

\subsection{Three-Dimensional Analysis: Distinct Element Modeling and Sensitivity Analysis}


In this section, we present results of the sensitivity study conducted with 3DEC to address the importance of the fractures and rock matrix properties, as well as the $3 \mathrm{D}$ geometry of the fracture network to the hydromechanical response of the rock mass.

\subsubsection{Reference Case}

Best match was obtained for different values of initial normal stiffness and initial hydraulic aperture at HM1 and HM2 within fault $\mathrm{F}_{12}$ (Table 4 and Fig. 13a). In the best match solution, fracture properties are assumed to be equal to that of HM1 in the entire fracture except to a radius of about $30 \mathrm{~cm}$ from HM2, where the HM2 properties are assumed. The initial-normalstiffness value at HM2 is a factor of 3 higher than at HM1, and the initial-hydraulic-aperture value at HM2 is a factor of 2 lower than at HM1. These best-fitting parameters were verified both at HM1 and HM2, while simulating two other pulse tests. A pulse of $9 \mathrm{kPa}$ at HM1 and a pulse of $35 \mathrm{kPa}$ at $\mathrm{HM} 2$ were simulated. The two simulations (Fig. 13b and 13c) yielded best match to field data for fracture hydromechanical parameters similar to the ones previously obtained with the pulse of $86 \mathrm{kPa}$ (Table 4). This model verification confirms that the hydromechanical properties varied by a factor of 2 to 3 for the two points spaced 1 meter apart along the same fracture plane.

The best-fit solution (Fig. 13a) indicates that the pressure gradient caused by the injection is mainly distributed in the pressurized fault. Nevertheless, part of the fluid flow occurs within the bedding plane $\left(\mathrm{S}_{7}\right.$ and $\left.\mathrm{S}_{8}\right)$ close to HM1 and HM2. During the pulse-pressure increase, fluid flow within the bedding planes induces a progressive mechanical opening along these planes (Fig. 14). In the vicinity of the pressurized fault, the normal displacement of bedding planes reaches a significant value by higher magnitude $\left(\Delta U_{n}=6 \times 10^{-7} \mathrm{~m}\right)$ than the one for the fault at HM2 (Fig. 14). In addition, fault opening causes shearing along bedding planes whose magnitude $\left(\Delta \mathrm{U}_{\mathrm{s}}=4.25 \times 10^{-7} \mathrm{~m}\right)$ is of the same order as the normal displacement at HM2. 
During pressure-pulse decrease at the injection point, progressive bedding plane opening still occurs far from the pressurized fault, whereas near the fault, bedding planes tend to close

(Fig. 14). This is caused by the propagation of the pressure within the bedding planes, in which pressure increases away from the injection point with a certain time delay. This induces delayed mechanical displacement.

In summary, this best-fit case shows a slight difference in fracture hydromechanical properties for two nearby points within the same fault plane. During a pulse injection test, hydromechanically and mechanically induced fracture shear and normal deformations occur in bedding planes and faults within the rock mass surroundings the tested fracture. These effects contribute significantly to accommodate the deformation of the pressurized fracture, and can therefore explain the difference between the back-calculated fracture normal stiffness with the three-dimensional single fracture axisymmetric model $\left(\mathrm{k}_{\mathrm{nF}}=8 \mathrm{GPa} / \mathrm{m}\right)$ and the stiffness obtained using the three-dimensional fracture-network model $\left(\mathrm{k}_{\mathrm{nF}}=17 \mathrm{GPa} / \mathrm{m}\right)$. This best-fit solution is used as a reference case in a sensitivity study presented below to address the importance of each hydromechanical parameter, as well as the importance of the fracturenetwork geometry with respect to the hydromechanical response of the pressurized fault $F_{12}$ in HM1 and HM2. The properties of faults $F_{11}$ and $F_{n}$ are assumed to be identical to those at HM1.

\subsubsection{Effects of Tested Fault Hydraulic Aperture and Normal Stiffness}

The initial normal stiffness of the fault strongly affects the normal displacement-versus-fluid pressure response at HM1 (Fig. 15a). If the fault normal stiffness is lower than the reference value $\left(\mathrm{k}_{\mathrm{nF}}=17 \mathrm{GPa} / \mathrm{m}\right)$, the normal displacement and the thickness of the loop increase. Conversely, if the normal stiffness value is higher, the normal displacement and the loop thickness decrease. The results for variation of fracture normal stiffness, shown in Fig. 15a, is consistent with the results obtained in the previous axisymmetric analysis shown in Figure 
12c. At HM2, the hydromechanical response follows the same variation as at HM1, but the magnitude of displacement is lower, because of the difference in initial normal stiffness between the two points (Fig. 16a).

At HM1, a variation in the fault initial hydraulic aperture by a factor of 10 has a significant influence on both the magnitude of normal displacement and the loop thickness (Fig. 15b). The larger the initial hydraulic aperture, the higher the magnitude of normal displacement. For a larger initial aperture, fluid pressure penetrates farther into the fracture for a given well pressure and time increment. The fact that the fluid pressure penetrates farther for a larger initial aperture can be observed as a higher magnitude of fluid pressure at HM2. The more widespread the pressure increase (with a larger radius of influence), the greater the force on the fracture surfaces, which in turn induces additional fracture opening. Moreover, if the initial hydraulic aperture of the pressurized fault is large compared to intersecting beddingplane apertures, fluid flow and pressure-deformation predominantly takes place within the fault.

If, on the other hand, the initial hydraulic aperture of the pressurized fault is equal or close to bedding-plane apertures (aperture of all bedding planes is $1 \times 10^{-5} \mathrm{~m}$ for the results in Fig. 15b), a significant amount of water leaks into intersecting bedding planes. This means that fluid pressure will not penetrate as far along the fault, but will rather leak into intersecting bedding planes, and then the pressure-deformation coupling occurs in the entire network. Modeling results indicate that the permeability contrast between the pressurized fault and bedding planes also affects the pressure-displacement responses in HM2 (Fig. 16b). Note, figure $16 \mathrm{~b}$ shows that the hydraulic aperture of the pressurized fracture strongly affects the magnitude of fluid pressure seen in HM2, whereas other parameters have negligible effect. Thus, the aperture value of $1 \times 10^{-4} \mathrm{~m}$, which was obtained from previous field experiments of the site, is verified by the good match in Figure $16 \mathrm{~b}$. 


\subsubsection{Hydraulic Apertures and Normal Stiffnesses of Four Bedding Planes}

Variation of bedding-plane normal stiffness from 50 to $200 \mathrm{GPa} / \mathrm{m}$ has no significant effect on the hydromechanical response at HM1 or HM2 (Fig. 15c-16c). A bedding-plane stiffness value equal to that at the fault has a minor effect at HM1.

A decrease in bedding-plane initial hydraulic aperture by a factor of 10 has no effect on the displacement-pressure response (Fig. 15d-16d). A hydraulic-aperture increase by a factor of 5 causes a slight decrease of normal displacement at HM1, and a slight decrease of normal displacement and fluid pressure at HM2. This is also caused by the fact that the fluid pressure effect on fault deformation depends on the hydraulic aperture contrast between the main fault and the bedding planes. As discussed in Section 5.4.1, if the bedding-plane apertures are equal or close to the initial hydraulic aperture of the pressurized fault, a significant amount of the injected water leaks into intersecting bedding planes. Since leakage into bedding planes reduces the amount of fluid flowing along the fracture, it prevents fluid pressure from penetrating farther in the fracture. A smaller radius of influence results in a smaller fracture opening, because the pressurized fracture area is smaller, and thereby the total force exerted on the fracture walls is smaller. This behavior is qualitatively the same as that obtained for leakage into a highly permeable rock matrix in the previous ROCMAS simulations (see Fig. $12 \mathrm{e})$.

\subsubsection{Young's Modulus of Rock Matrix}

A decrease in the Young's modulus by a factor of 1.5 or 2 significantly increases the normal displacement (by several microns) at HM1 (Fig. 15e). An increase of the Young's modulus by a factor of 1.5 slightly decreases the normal displacement at HM1. Again, the results are in qualitative agreement with the results obtained in the previous axisymmetric ROCMAS analysis (Fig. 12d). The magnitudes of pressure changes, on the other hand, are not affected. 
At HM2, varying the Young's modulus induces a small change in displacement magnitude (Fig. 16e), because the higher stiffness at HM2 restricts the effect of rock matrix deformation on fracture deformation.

\subsubsection{Geometry of the Fractures Network}

The effects of fracture network geometry on the hydromechanical response of the pressurized fault $\left(\mathrm{F}_{12}\right)$ were highlighted by comparing the following three numerical cases (Fig. 8):

- Fault $\mathrm{F}_{12}$ embedded in the intact rock matrix (Case I)

- Faults $\mathrm{F}_{11}, \mathrm{~F}_{\mathrm{n}}, \mathrm{F}_{12}$, and no bedding planes (Case II)

- Bedding planes $\mathrm{S}_{7}, \mathrm{~S}_{8}, \mathrm{~S}_{9}, \mathrm{~S}_{10}$ and fault $\mathrm{F}_{12}$ (Case III).

Results presented for points HM1 (Fig. 15f) and HM2 (Fig. 16f) show that Case I, with the pressurized fault, $\mathrm{F}_{12}$, embedded in intact rock matrix, matches the experimental values only for the pulse-pressure increasing part. Thus, under the initial pressure increase, the near-wellbore intrinsic hydromechanical properties of fault $F_{12}$ and the mechanical properties of the surrounding rock matrix control the fault behavior. For the subsequent pressure-decreasing part, on the other hand, Case I underestimates the fracture opening because the opening is restricted by the relatively stiff rock matrix. Case II, which includes faults and intact rock matrix, but neglects the bedding planes, matches the field data for the pulse-pressure increase and half of the pulse-pressure decrease. Qualitatively, the different pressure-versusdisplacement behavior for Case I and Case II is consistent with the results in Fig. $12 \mathrm{f}$ for adjacent parallel fractures. This result confirms that the adjacent faults $\left(F_{11}\right.$ and $\left.F_{n}\right)$ affect the hydromechanical response of the pressurized fault during the pulse-pressure decrease stage. Case III, which includes the four bedding planes and the fault $F_{12}$ but neglects the parallel faults $\left(F_{11}\right.$ and $\left.F_{n}\right)$, does not match the measurements. Normal displacement is overestimated because the additional shearing that occurs along bedding planes causes an amplification of the fault mechanical aperture. 


\subsection{Comparison of 3DEC and ROCMAS Best-Fit Model Parameters}

The 3DEC and ROCMAS mechanical parameters back-calculated by fitting field data (Table 4) are consistent in the sense that ROCMAS represents all discontinuities surrounding the pressurized fracture as an equivalent continua. The fracture and rock matrix stiffness values back-calculated in ROCMAS are thus lower than the ones obtained with 3DEC. The difference in back-calculated fracture normal stiffness $(8 \mathrm{GPa} / \mathrm{m}$ for ROCMAS and $17 \mathrm{GPa} / \mathrm{m}$ for 3DEC) can be directly linked to the contribution from the deformability of fractures in the surrounding rock mass, and in particular to the shear deformations in intersecting beddingplanes. In the 3DEC analysis, shear displacements along bedding-planes accommodate additional deformation at HM1, as described in Figure 14c. In the 3DEC analysis, a higher fracture normal stiffness of the main fracture offsets the effect of this bedding-plane sheardisplacement. However, the ROCMAS best-fitting mechanical parameters are equivalent parameters that allow the restoration of mechanical deformations caused by adjacent fractures. Thus, with both a discrete or continuum model, a reasonable range of values is obtained, provided that the effective parameters account for mechanical deformations being accommodated by the surrounding discontinuities.

\section{Discussion}

\subsection{Implications for In Situ Determination of Hydromechanical Properties}

The two-dimensional plane strain and axisymmetric analyses, and the three-dimensional fracture-network analysis, identify the key parameters that influence field-test results (Table 5). The analyses indicate that the two most important parameters determining the normal displacement-versus-pressure responses are the fracture normal stiffness and the Young's modulus of the intact rock. In addition, the initial aperture of the fault is an important 
parameter that (in this case) had been determined from previous hydraulic tests at the site. Both the fracture normal stiffness and the stiffness of the surrounding rock mass (represented by the Young's modulus) affect the general form of the normal displacement-versus-pressure curve. However, the width of the loop-shaped evolution of the normal displacement-versuspressure curve is mainly a function of the contrast between the fracture and rock-matrix mechanical properties. Because the loop shape is controlled by this stiffness contrast, it might be possible to uniquely determine both fracture normal stiffness and an equivalent modulus of the surrounding rock mass by examining both the inclination and width of the loop. However, such an analysis would require accurate modeling of the full loop of both increasing pressure and decreasing pressure in an ideal radial-symmetric-flow situation. The sensitivity analysis indicates that if one or several highly permeable fractures intersect the pressurized fracture close to the injection point, leakage may induce significant deviations from this ideal solution and lead to significant error in the back-calculated stiffness values. Furthermore, shear slip along bedding planes intersecting the pressurized fault can result in additional fracture opening near the well bore, which would impact the back-calculated hydromechanical properties of the pressurized fault.

\subsection{Heterogeneity of Fracture Hydromechanical Properties}

The current study demonstrates that fracture hydromechanical properties, such as hydraulic aperture and normal stiffness, can vary by a factor of 2 to 3 along the same plane. This difference could be explained by the complex internal geometry of voids and by the distribution of the amount and size of the contact surface area within the fracture plane. Such variability of fracture hydromechanical properties, with pressure distribution and fracture normal stiffness implicitly linked to the geometry of void space and contact area, has also been observed for single joints at the laboratory scale [14-15]. For example, Hopkins et al. 
[61] show that joint normal stiffness in laboratory samples can vary over several orders of magnitude, along with the percentage of contact area within the joint. On a larger scale, measurements of fault aperture in the field have shown that a shear offset results in an undulating pattern of variable fracture aperture [44,62]. Faults would then be represented better with a variable width of void space and a variable contact area, to take into consideration the variability of hydraulic aperture and normal stiffness [17-18,23,63]. Moreover, this geometry could also allow consideration of channelling within the fault plane. Channelling can induce a so-called insufficient effect of pressure rise, in which pressure rise can induce variable displacement along the fault plane, like those observed at HM1 and HM2. This effect has been experimentally observed at the laboratory scale and physically linked to the discontinuity morphology [64-65]. Therefore, if at all possible, hydraulic tests such as interference tests should be performed at different points to characterize the fracture inhomogeneous hydraulic and mechanical properties. Thus, one measuring point may not be sufficient as a representative value over the fracture plane.

\subsection{Contribution of the Hydromechanical Analysis to Accurately Estimate Fracture Hydraulic}

\section{Aperture}

Commonly, the determination of hydraulic aperture of a fracture using pulse test data is made by curve-matching techniques [45-50]. In these approaches, fracture permeability is determined by matching the pulse-pressure-decreasing stage to type curves, with the effects of hydromechanical processes lumped into an "effective" fracture storativity value. Fracture hydraulic aperture is then derived from permeability, using the cubic law [60]. Compared to these techniques, our modeling approach analyzes all the pressure curves and indicates that the pressure decrease path of a pulse test is highly influenced by mechanical processes within a larger portion of the surrounding fractured rock, whereas the pressure increase path of the 
normal displacement-versus-pressure curve allows us to constrain the determination process of the tested-fracture's hydromechanical properties. Thus, the pressure-decrease path used in the analytical techniques is not representative of the behavior of the tested fracture and therefore provides equivalent properties of the surrounding fractured rock. To avoid such misinterpretations, the analytical solutions should be adapted to include an analysis of the pulse-pressure-increase stage, which provides an accurate estimate of the hydraulic aperture of the tested fracture. Additionally, in the evaluation process, displacement-versus-pressure measurements can be used to constrain fracture storativity. Indeed, Rutqvist et al. [37] show that in the fracture, the water storage is dominated by the fracture deformation. Thus, with coupled pressure and displacement measurements across the fracture, we could obtain a reasonable range of intrinsic hydraulic properties for the tested fracture. The high-frequency simultaneous measurements of the fluid pressure and mechanical displacement changes are useful in monitoring the complete transient hydromechanical reactions that a fracture might undergo during a pulse injection test, and in providing a substantially improved estimate of fracture hydraulic aperture. The complete pressure-time and normal displacement-time curves, including increasing and decreasing stages, are necessary for an accurate analysis of this type of pulse test.

\subsection{Mechanical Behavior of the Rock Mass Surrounding the Pressurized Fracture}

The loop-shaped normal displacement-versus-pressure curve clearly gives two distinct kinds of information about the tested fracture zone. Modeling shows that a hydromechanical analysis of the pulse-pressure-increase stage can provide an estimate of fracture hydromechanical properties, provided that the Young's modulus of the rock matrix is known. Moreover, the pulse-pressure-decrease stage is affected by the hydraulic and mechanical properties of the surrounding fractured rock mass. Comparison between the three-dimensional 
best-fit model and the simpler models shows that aperture closure and shearing would occur in discontinuities surrounding the pressurized fault $\mathrm{F}_{12}$ - and these may have a significant impact on the hydromechanical response of the tested discontinuity. This means that the pressure-decrease stage of a pulse test could be used to characterize the equivalent mechanical properties of the rock mass surrounding the tested discontinuity, which includes the composite effect of fracture network geometry and the porous rock matrix.

\section{Conclusions}

Pulse testing with high-frequency measurements of fluid pressure and mechanical displacement has been shown to be a useful new method for in situ characterization of fractured-rock masses. The method can be used to determine hydraulic aperture and normal stiffness of fractures, as well as the equivalent stiffness of the surrounding rock mass. However, evaluation of such a pulse injection test by hydromechanical modeling should be performed with great care, because the fracture system response is complex. The tests can be evaluated by models considering either a discrete fracture medium, or an idealized medium made up of a pressurized fracture embedded in an equivalent rock medium that reproduces the behavior of the surrounding fractured rock. Potential misinterpretations of fracture hydraulic aperture by conventional curve matching of pulse-pressure data can be avoided with an appropriate hydromechanical analysis of the complete pressure-time and displacement-time curves, including results from both the pressure-increasing and pressure-decreasing stages.

\section{Acknowledgments}

The authors acknowledge with gratitude the financial support of the INERIS within the framework of the BCRD-DRS02 scientific program. The fifth co-author thanks Géosciences Azur team for the quality of the work done with the financial support. The third and fourth co- 
authors would like to acknowledge support by the Office of Science, Office of Basic Energy

Sciences, Chemical Sciences and Geosciences Division of the U.S. Department of Energy, under Contract No. DE-AC03-76SF00098. Publication no. 808 of Geosciences Azur Lab.

\section{References}

[1] Louis C.L. A study of Groundwater Flow in Jointed Rock and Its Influence on the stability of Rock Masses Imperial College, Rock Mech. Research Report No. 10, 1969.

[2] Goodman R.E. Deformability of joints. In : Proc. Symp. Determination of the In-situ Modulus of deformation of rock, 2-7 February, Denver, Colorado. ASTM Spec. Tech. Publ., 1970;477:174-196.

[3] Jones O.F. A laboratory study of the effects of confining pressure on fracture flow and storage in carbonate rocks. J. Pet. Technol., 1975;27:21-27.

[4] Zoback M.D., Byerlee J.D. Permeability and effective stress. AAPG Bull., 1975;59:154-158.

[5] Gale J. A numerical, field and laboratory study of flow in rock with deformable fractures. PhD Thesis, University of California, Berkeley, 1975, 143 p.

[6] Goodman R.E. Methods of geological engineering in discontinuous rocks. New York, West Publishing Company, Goodman, 1976.

[7] Tsang Y.W., Witherspoon P.A. Hydromechanical Behavior of a Deformable Rock Fracture Subject to Normal Stress. J. Geophys. Res., 1981;86:9287-9298.

[8] Tsang Y.W., Witherspoon P.A. The dependence of fracture mechanical and fluid flow properties of fracture roughness and sample size. J. Geophys. Res., 1983;88:2359-2366.

[9] Bandis S.C., Lumsden A.C., Barton N. Fundamentals of rock joint deformation, Int. J. Rock Mech. Min. Sci. \& Geomech. Abstr., 1983;20:249-268.

[10] Raven K.G., Gale J.E. Water flow in a natural rock fracture as a function of stress and sample size. Int. J. Rock. Mech. Min. Sci. \& Geomech. Abstr., 1985;22:251-261.

[11] Pyrak-Nolte L., Myer L.J, Cook N.G.W., Witherspoon P.A. Hydraulic and mechanical properties of natural fractures in low permeability rock. In: Herget G., Vongpaisal S (eds) Proc. $6^{\text {th }}$ Congr. International Society of Rock Mechanics, Montréal. Balkema, Rotterdam, 1987;1:225-231.

[12] Makurat A., Barton N., Rad N.S. Joint conductivity variation due to normal and shear deformation. In: Barton N, Stephansson O (eds) Rock Joints. Balkema, Rotterdam, 1990:535-540.

[13] Cook N.G.W. Natural Joints in Rock: Mechanical, Hydraulic and Seismic Behavior and Properties under Normal Stress. In Jaeger Memorial Dedication Lecture, Int. J. Rock. Mech. Min. Sci. \& Geomech. Abstr., 1992;29:198-223.

[14] Henry J.P., Sibai M. Couplage hydromécanique dans les joints rocheux sous sollicitations normales: proposition de modélisation et comparaison avec l'expérience. Expérimentation et Calcul en Génie Civil, 1997:47-54.

[15] Sibai M., Haji Sotoudeh M., Henry J.P. Etude expérimentale du couplage hydromécanique de joints rocheux. Revue française de géotechnique, 1997;81:33-39. 
[16] Hopkins D.L. The implications of joint deformation in analyzing the properties and behavior of fractured rock masses, underground excavations and faults. Int. J. Rock. Mech. Min. Sci., 2000;37:175-202.

[17] Pyrak-Nolte L.J., Morris J.P. Single fractures under normal stress: The relation between fracture specific stiffness and fluid flow. Int. J. Rock. Mech. Min. Sci., 2000;37:245-262.

[18] Myer L.R. Fractures as collections of cracks. Int. J. Rock. Mech. Min. Sci., 2000;37:231-243.

[19] Doe T.W., Korbin G.E. A comparison of hydraulic fracturing and hydraulic jacking stress measurements. $28^{\text {th }}$ US Symposium on Rock Mechanics, Tucson, 1987.

[20] Jung R. Hydraulic in situ investigation of an artificial fracture in the Falkenberg granite. Int. J. Rock Mech. Min. Sci. \& Geomech. Abstr., 1989;26:301-308.

[21] Gertsch L.S. Changes in in situ rock joint flow characteristics caused by mechanical displacement. In: Rock Mechanics Contributions and Challenges, Proceeding of $31^{\text {st }}$ U.S. Rock Mechanics Symposium, Hustrulid and Johnson (eds), A.A. Balkema, 1990:363-370.

[22] Martin C.D., Davison C.C., Kozak E.T. Characterizing normal stiffness and hydraulic conductivity of a major shear zone in granite. In: Barton N, Stephansson O (eds) Rock Joints. Balkema, Rotterdam, 1990:549-556.

[23] Myer L.R. Hydromechanical and seismic properties of fractures. In: Wittke W (ed) Proc. $7^{\text {th }}$ Int. Congr. Rock. Mechanics. Aagen, Germany. Balkema, Rotterdam, 1991:397-404.

[24] Cornet F.H., Morin R.H. Evaluation of hydromechanical coupling in a granite rock mass from a highvolume high-pressure injection experiment: Le Mayet de Montagne, France. Int. J. Rock Min. Sci. \& Geomech. Abstr., 1997;34: paper no. 207.

[25] Alm P. Hydro-mechanical behavior of a pressurized single fracture: an in situ experiment. PhD Thesis, Chalmers University of Technology, Sweden, 1999, 102 p.

[26] Cornet F.H., Li L., Hulin J.P., Ippolito I., Kurowski P. The hydromechanical behavior of a fracture: an in situ experimental case study. Int. J. Rock Min. Sci., 2003;40:1257-1270.

[27] Murdoch L.C., Schweisinger T., Svenson E., Germanovitch L. Measuring and analyzing transient changes in fracture aperture during well tests : preliminary results. Dynamics of Fluids in Fractured Rock. Witherspoon Conference, Feb. 10-14, 2004.

[28] Cappa F., Guglielmi Y., Fénart P., Merrien-Soukatchoff V., Thoraval A. Hydromechanical interactions in a fractured carbonate reservoir inferred from hydraulic and mechanical measurements. Int. J. Rock. Mech. Min. Sci., 2005;42:287-306.

[29] Schweisinger T., Svenson E., Murdoch L.C. Transient changes in fracture aperture during hydraulic well tests in fractured gneiss. Proceedings Georgia Water Resources Conference, K.J Hatcher (ed.), April 25-27, 2005

[30] Cappa F., Guglielmi Y., Gaffet S., Lançon H. Lamarque I. Use of in situ fiber optic sensors to characterize highly heterogeneous elastic displacement fields in fractured rocks. Int. J. Rock. Mech. Min. Sci. 2006;43:647654.

[31] Murdocq L.C., Germanovitch L. Analysis of a deformable fracture intersecting a well. Int. J. Num. An. Meth. Geom. (in press).

[32] Rutqvist J. Coupled stress-flow properties of rock joints from hydraulic field testing. PhD Thesis, Royal Institute of Technology, Sweden, 1995.

[33] Rutqvist J. Determination of hydraulic normal stiffness of fractures in hard rock from well testing. Int. J. Rock. Mech. Min. Sci. \& Geomech. Abstr., 1995;32:513-523.

[34] Rutqvist J. Hydraulic pulse testing of single fractures in porous and deformable rocks. Q. J. Eng. Geol. 1995;29:181-192. 
[35] Rutqvist J., Stephansson O. A cyclic hydraulic jacking test to determine the in situ stress normal to a fracture. Int. J. Rock. Mech. Min. Sci \& Geomech. Abstr. 1996;33:695-711

[36] Rutqvist J., Stephansson O., Tsang C.F. Hydraulic field measurements of incompletely closed fractures in granite. Int. J. Rock. Mech. Min. Sci \& Geomech. Abstr. 1997;34:3-4, Paper No. 267.

[37] Rutqvist J., Noorishad J., Tsang C.F., Stephansson O. Determination of fracture storativity in hard rocks using high-pressure injection testing. Water Resour. Res., 1998;34:2551-2560.

[38] Souley M., Homand F., Pepa S., Hoxha D. Damage-induced permeability changes in granite: a case example at the URL in Canada. Int. J. Rock. Mech. Min. Sci., 2001;38:297-310

[39] Rutqvist J., Wu Y.S., Tsang C.F, Bodvarsson G. A modeling approach for analysis of coupled multiphase fluid flow, heat transfer, and deformation in porous fractured rock. Int. J. Rock. Mech. Min. Sci., 2002;39:429442.

[40] Rutqvist J., Tsang C.F. Analysis of thermal-hydrologic-mechanical behavior near an emplacement drift at Yucca Mountain. J. Contaminant Hydrol. 2003;62-63 :637-652.

[41] Rutqvist J., Tsang C.F. A study of caprock hydromechanical changes associated with $\mathrm{CO}_{2}$-injection into brine formation. Environmental Geology, 2002;42(2-3):296-305.

[42] Zangerl C., Eberhardt E., Loew S. Ground settlements above tunnels in fractured crystalline rock: numerical analysis of coupled hydromechanical mechanisms. Hydrogeology Journal 2003;11:162-173.

[43] Jing L. A review of techniques, advances and outstanding issues in numerical modeling for rock mechanics and rock engineering. Int. J. Rock. Mech. Min. Sci., 2003;40:283-353.

[44] Rutqvist J., Stephansson O. The role of hydromechanical coupling in fractured rock engineering. Hydrogeology Journal, 2003;11:7-40.

[45] Cooper H.H., Bredehoeft J.D., Papadopulos I.S. Response of a finite-diameter well to an instantaneous charge of water. Water Resour. Res., 1967;3:263-269.

[46] Wang J.S.Y, Narasimhan T.N., Tsang C.F., Witherspoon P.A. Transient flow in tight fractures. Well Testing Symposium, Berkeley, 1977;103-116.

[47] Bredehoeft J.D., Papadopulos S. A method to determine the hydraulic properties of tight formations. Water Resour. Res., 1980;16:233-238.

[48] Barker J.A., Black J.H. Slug tests in fissured aquifers. Water Resour. Res., 1983;19:1558-1564.

[49] Black J.H. The interpretation of slug tests in fissured rocks. Q. J. Eng. Geol. 1985;18:161-171.

[50] Barker J.A. A Generalized Radial Flow Model for Hydraulic Testing in Fractured Rock. Wat. Resour. Res., 1988;24(10):1796-1804.

[51] Tsang C.F. Linking thermal, hydrological, and mechanical processes fractured rocks. Annu. Rev. Earth. Planet. Sci., 1999;27:359-384.

[52] Guglielmi Y., Mudry J. Quantitative measurements of channel-block hydraulic interactions by experimental saturation of a large, natural, fissured rock mass. Ground Water, 2001;39:696-701.

[53] RocTest-Telemac. Retrievable borehole extensometer, Model BOF-EX, Instruction manual (E1004C040609), 2004:1-7.

[54] Noorishad J., Tsang C.F., Witherspoon P.A. Theoretical and field studies of coupled hydromechanical behavior of fractured rocks - 1. Development and verification of a numerical simulator. Int. J. Rock. Mech. Min. Sci \& Geomech. Abstr. 1992;29:401-409. 
[55] Rutqvist J., Noorishad J., Stephansson O., Tsang C.F. Theoretical and field studies of coupled hydromechanical behavior of fractured rocks -2 . Field experiments and modeling. Int. J. Rock. Mech. Min. Sci \& Geomech. Abstr. 1992;29:411-419.

[56] Biot M.A. General theory of three dimensional consolidation. Journal of Applied Physics. 1941;12:155-164.

[57] Cundall P.A., Hart R.D. Development of Generalized 2-D and 3-D Distinct Element programs for Modeling jointed Rock. Itasca Consulting Group; U.S Army Corps of Engineers, Misc. Paper SL-85-1, 1985.

[58] Cundall P.A. Formulation of a three-dimensional distinct element model-Part I. A scheme to detect and represent contacts in a system composed of many polyhedral blocks. Int. J. Rock Mech. Min. Sci. \& Geomech. Abstr. 1988;25:107-116.

[59] Itasca Consulting Group, Inc. 3DEC 3-Dimensional Distinct Element Code. Minneapolis : ICG. 2003.

[60] Witherspoon P.A., Wang J.S.Y, Iwai K., Gale J.E. Validity of Cubic Law for Fluid Flow in a Deformable Rock Fracture, Water Resour. Res., 1980;16:1016-1024.

[61] Hopkins D.L., Cook N.G.W., Myer L.R. Normal joint stiffness as a function of spatial geometry and surface roughness. In: Barton N, Stephansson O (eds) Rock Joints. Balkema, Rotterdam, 1990;203-210.

[62] Hakami E. Aperture distribution of rock fractures. PhD Thesis, Royal Institute of Technology, Sweden, 1995.

[63] Hesler G.J, Zheng Z., Myer L.R. In situ fracture stiffness determination. In: Rock Mechanics Contributions and Challenges, Proceeding of $31^{\text {st }}$ U.S. Rock Mechanics Symposium, Hustrulid and Johnson (eds), A.A. Balkema, 1990;405-412.

[64] Zimmerman R.W., Chen D.W., Long J.C.S., Cook N.G.W. Hydromechanical coupling between stress, stiffness and hydraulic conductivity of rock joints and fractures. In: Barton N, Stephansson O (eds) Rock Joints. Balkema, Rotterdam, 1990.

[65] Sibai M., Haji Sotoudeh M., Henry J.P. Etude expérimentale du couplage hydromécanique de joints rocheux. Revue française de géotechnique, 1997;81:33-39.

\section{Figure captions}

Fig. 1. (a) Three-dimensional view of the fractured rock mass at the Coaraze Laboratory Site; (b) stereonet of plots to discontinuities.

Fig. 2. Experimental device used for hydraulic pulse tests.

Fig. 3. Results of a pulse test applied to HM1: (a) pressure and normal displacement at points HM1 and HM2 as a function of time (the pressure prior to the test is of $39 \mathrm{kPa}$ at HM1 and $27 \mathrm{kPa}$ at HM2); (b) normal displacement as a function of pressure showing loop-like behavior; (c) repeatability of the loop-like behavior for three pulses of same magnitude $(\Delta \mathrm{P}=86 \mathrm{kPa})$ applied at $\mathrm{HM} 1$.

Fig. 4.Normal displacement as a function of pressure at pulse-peak for each 70 pulse tests. 
Fig. 5. Geometry and boundary conditions of the two-dimensional numerical models; (a) axisymmetric models of a single vertical fracture used for the code intercomparison, and the two-dimensional analysis (models $2 \mathrm{DAxM}_{1}$ to $2 \mathrm{DAxM}_{5}$ ); (b) full section of the Coaraze rock mass (model CSM).

Fig. 6. Finite element mesh assigned to ROCMAS model: (a) entire model; (b) close-up vertical x-z section around the injection point.

Fig. 7. Geometry of the three-dimensional numerical models; (a) axisymmetric model of a single vertical fracture (model 3DAxM); (b) 3DEC model of the fractures network around the HM1 injection point (model 3DFM); (c) boundary conditions used in 3DEC models and presented along a diagonal section aligned on HM1 and HM2 (dashed line in $7 b)$.

Fig. 8. 3D numerical models used in the sensitivity study to address the importance of the geometry of the fracture network on the hydromechanical response.

Fig. 9. Normal displacement-versus-pressure curves during pulse injection: (a) two-dimensional plane strain case simulated with ROCMAS, UDEC, and 3DEC; and (b) three-dimensional axisymmetric analysis simulated with ROCMAS and 3DEC.

Fig. 10. Normal displacement-versus-pressure curves for (a) idealised model geometry with the pressurised fracture embedded in a homogeneous rock mass; (b) full two-dimensional model geometry.

Fig. 11. The ROCMAS solution for an axisymmetric model of the pressurised fracture embedded in an elastic rock mass. The initial fracture aperture is $1 \times 10^{-4} \mathrm{~m}$, and the equivalent radius of influence is $3.9 \mathrm{~m}$.

Fig. 12. Pulse test analysed using ROCMAS at HM1 while varying (a) mechanical boundaries; (b) equivalent radius of influence; (c) fracture normal stiffness; (d) Young's modulus of rock matrix; (e) leakage into rock matrix; (f) adjacent fault.

Fig. 13. Pulse test analysed using 3DEC with best-fit parameters for (a) reference case; (b) HM1 parameters from the reference case used for a pulse magnitude of $9 \mathrm{kPa}$ at HM1; (c) HM2 parameters from the reference case used for a pulse magnitude of $35 \mathrm{kPa}$ at HM2.

Fig. 14. (a-b) Simulated shear displacement along bedding planes during the pressure pulse at HM1; (c-d) 2D conceptual model of deformation along bedding planes during the pressure pulse at HM1.

Fig. 15. 3DEC analysis of a pulse test applied to HM1 while varying (a) initial normal stiffness at HM1 ( $k_{n}$ ); (b) initial hydraulic aperture at HM1 $\left(B_{h i}\right)$; (c) initial normal stiffness of bedding planes $\left(k_{n} B P\right)$; (d) initial hydraulic aperture of bedding planes $\left(B_{h i} B P\right)$; (e) Young's modulus of rock matrix $\left(E_{R}\right)$; (f) geometry of the fracture network (CASES I, II, III). 
Fig. 16. 3DEC sensitivity analysis at HM2 for a pulse test applied to HM1 while varying (a) initial normal stiffness at HM1 $\left(k_{n F}\right)$; (b) initial hydraulic aperture at HM1 $\left(B_{h i}\right)$; (c) initial normal stiffness of bedding planes $\left(k_{n}{ }_{B P}\right)$; (d) initial hydraulic aperture of bedding planes $\left(B_{h i}{ }_{B P}\right)$; (e) Young's modulus of rock matrix $\left(E_{R}\right)$; (f) geometry of the fractures network (CASES I, II, III).

Table 1. Codes, models, and tested parameters in each numerical approach.

Table 2. Material properties used in the code comparison.

Table 3. Material properties used in the two-dimensional full-section analysis.

Table 4. Material properties used in the two-dimensional ROCMAS axisymmetric analysis and in the 3DEC full fracture network analysis.

Table 5. Importance of each parameter for the sensitivity of the hydromechanical response. 


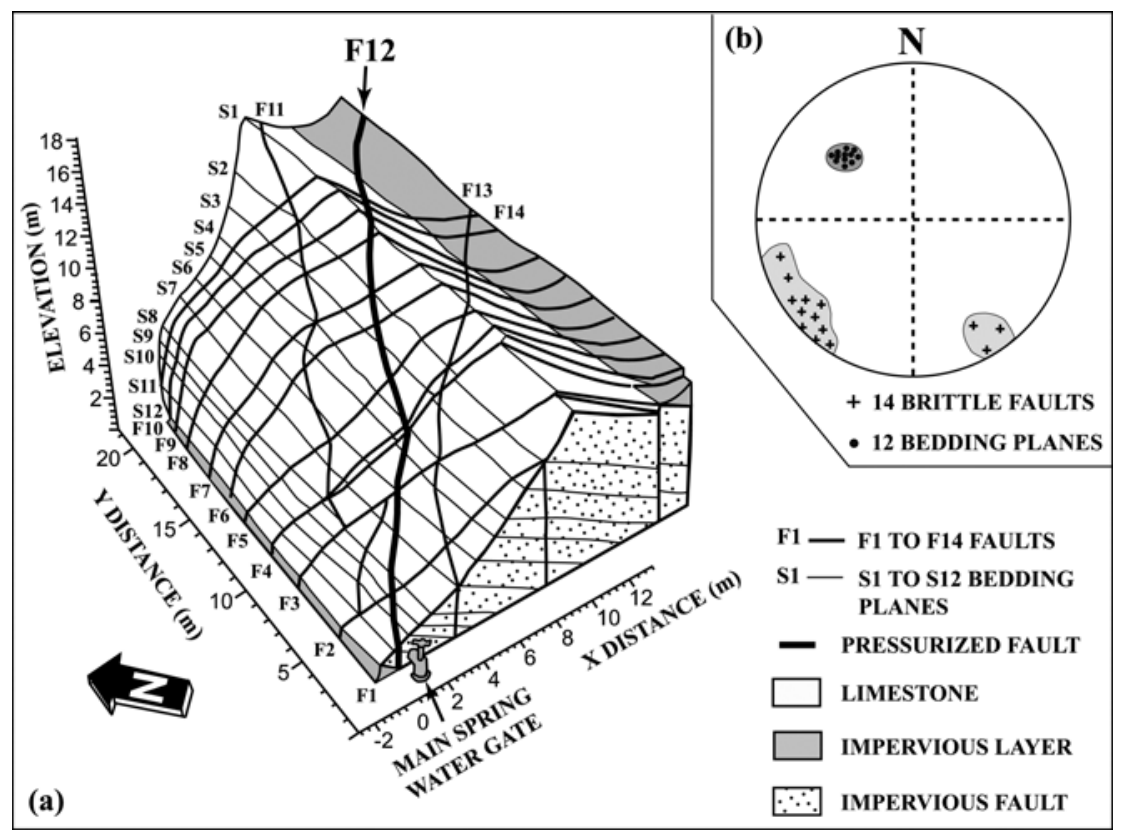

Fig. 1 


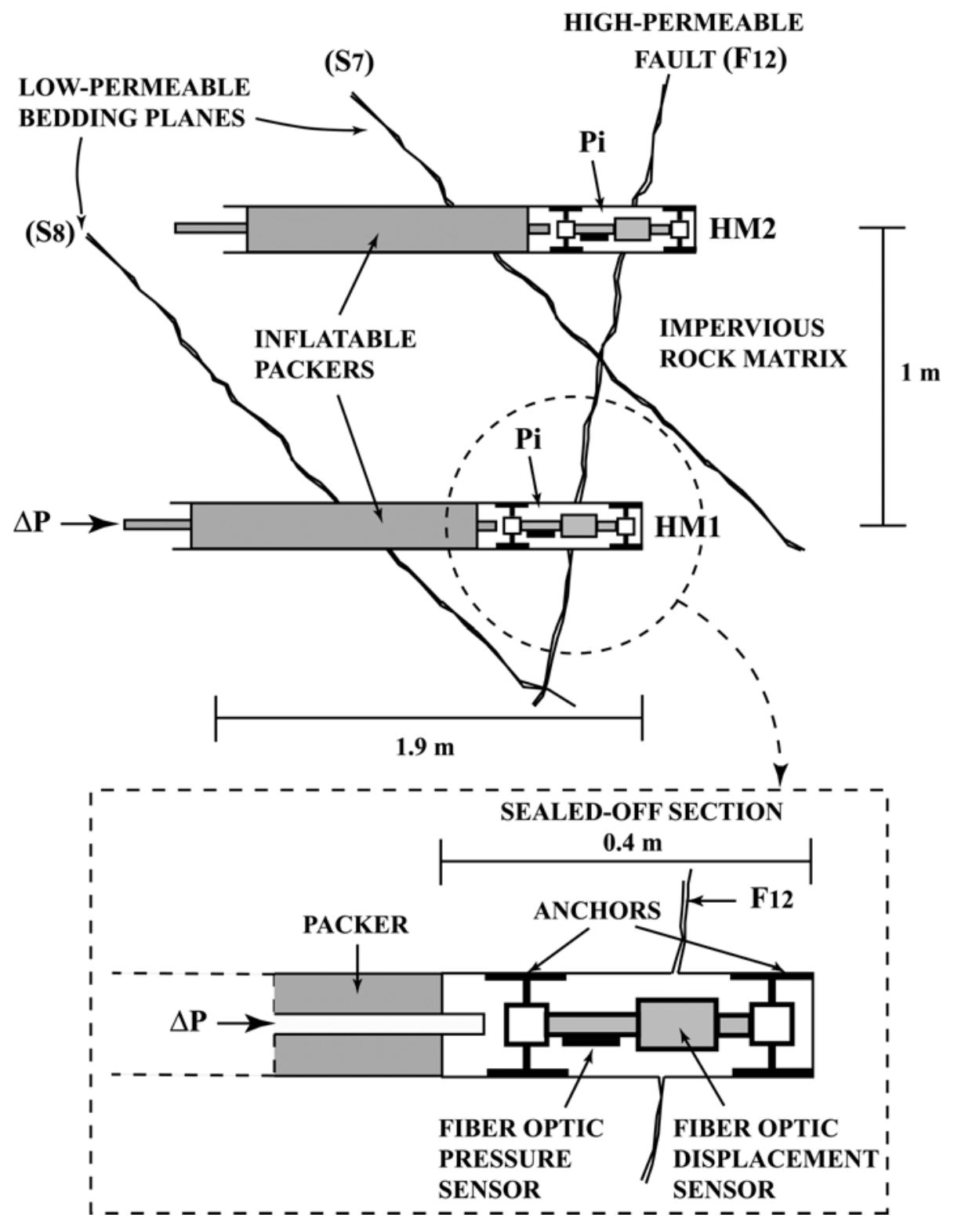

Fig. 2 

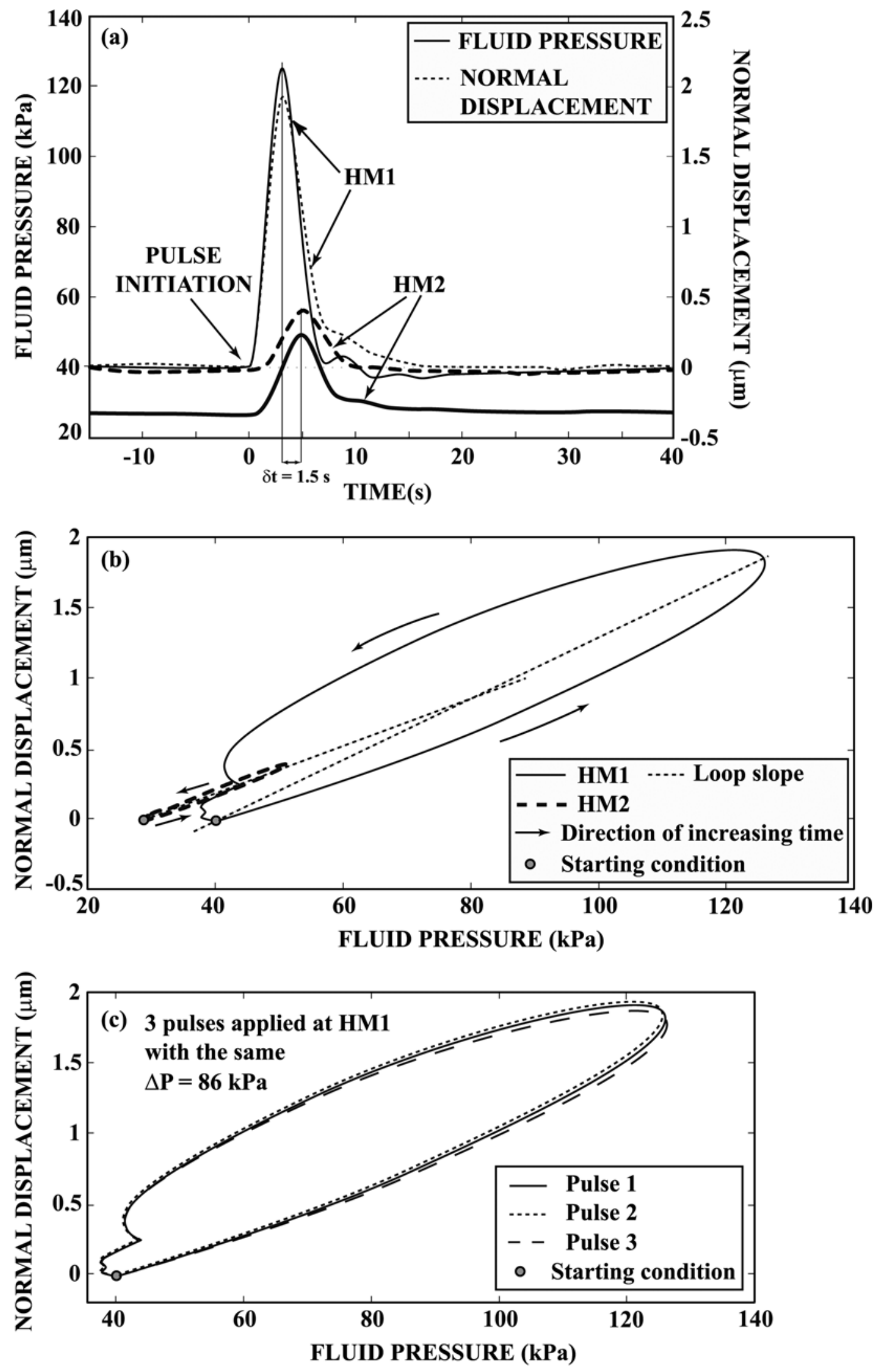

Fig. 3 


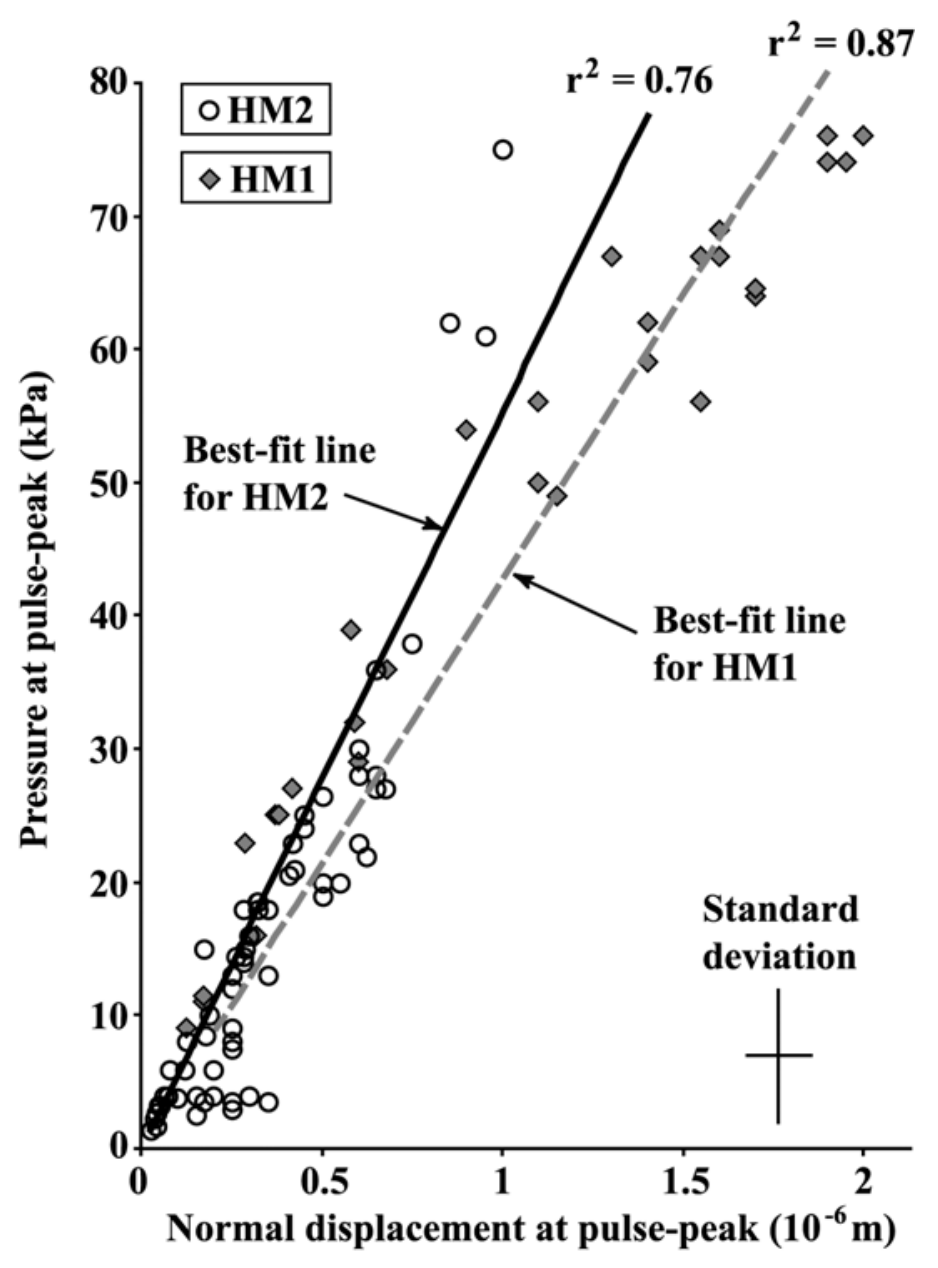

Fig. 4 

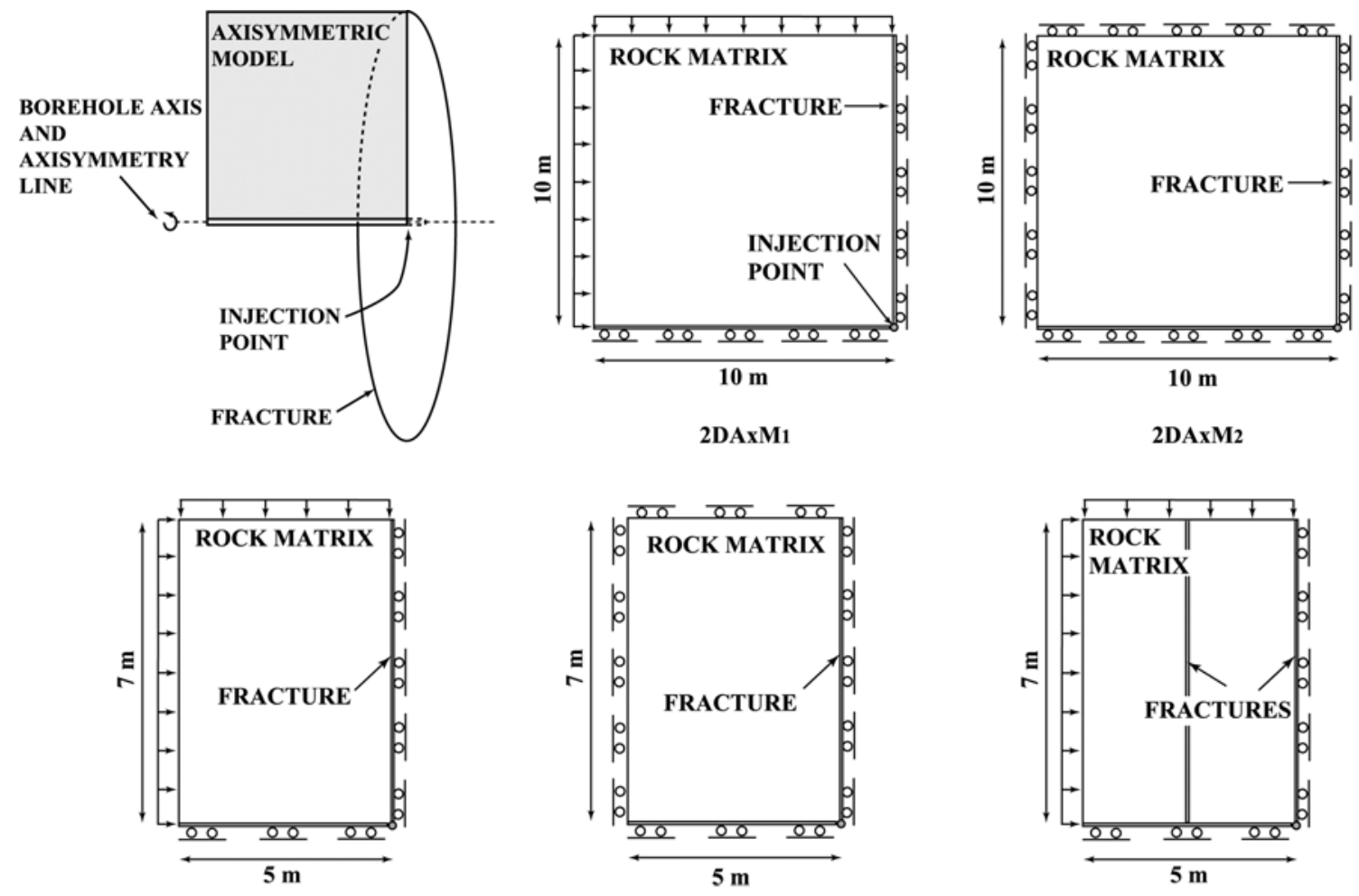

2DAxM3

2DAxM4

2DAxM5

(a)

Impermable geological boundaries

Calcareous rock matrix

High-permeable faults

Low-permeable bedding planes

e. Null displacement normal to the boundary

[ Constant stress

boundary

Natural water level

- - - (water only within

fractures)

Geometrical boundaries of the 3DEC model

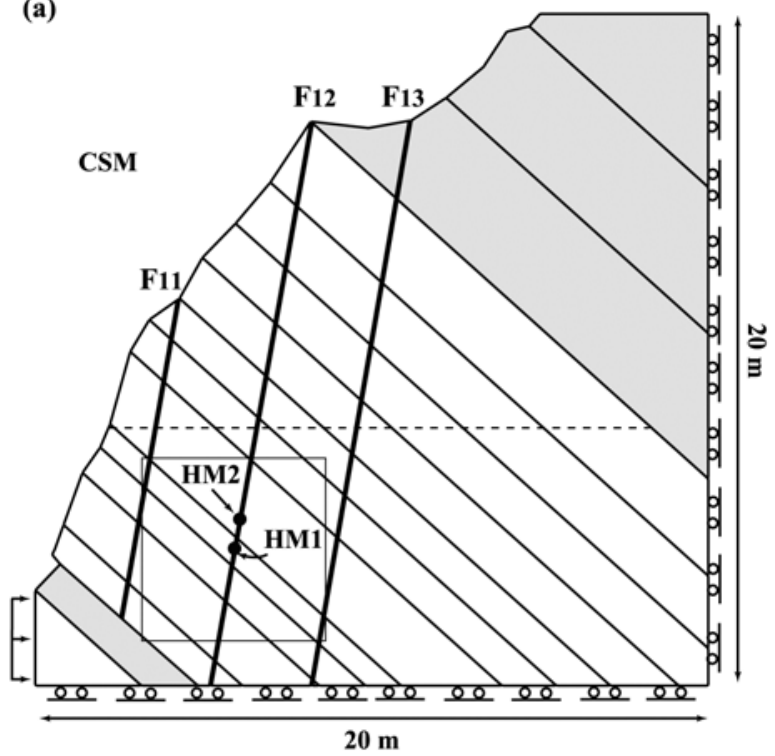

(b)

Fig. 5 


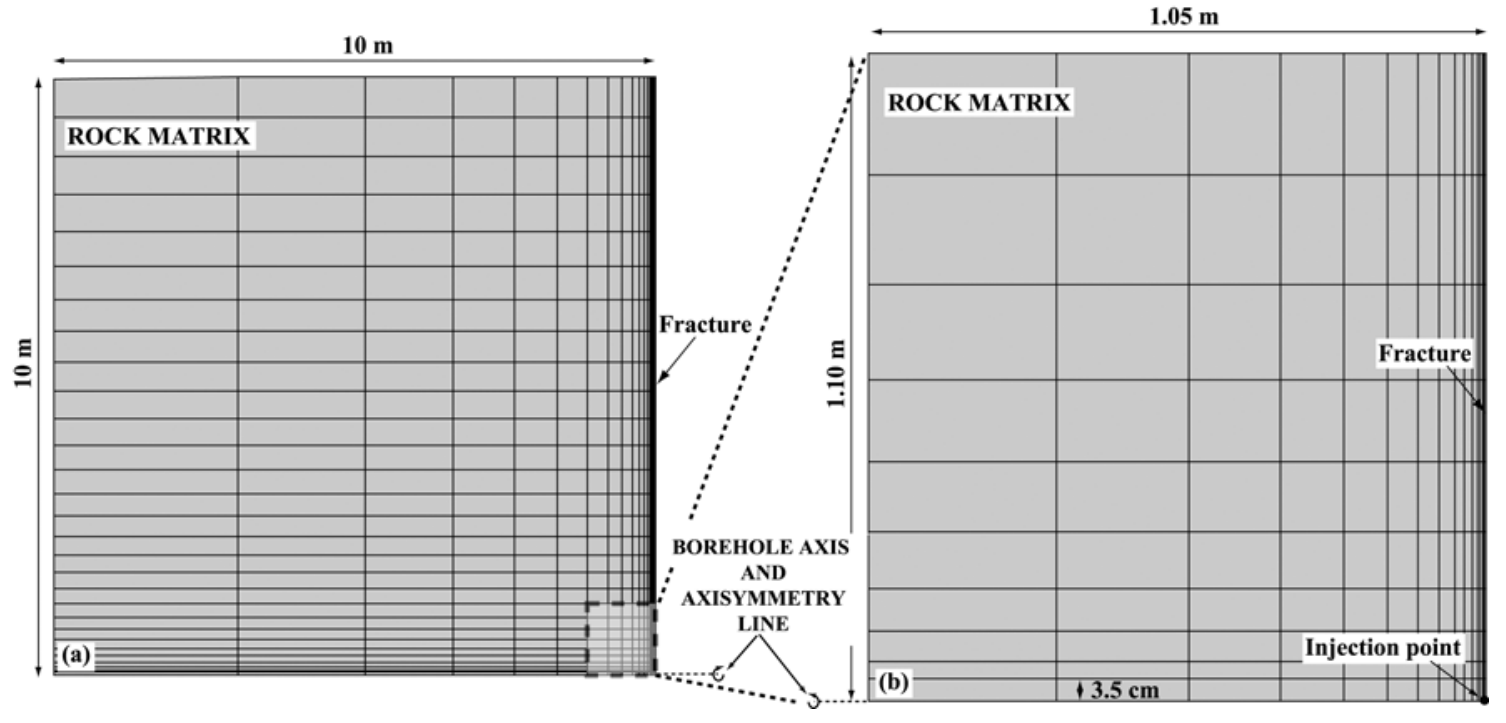

Fig. 6. 


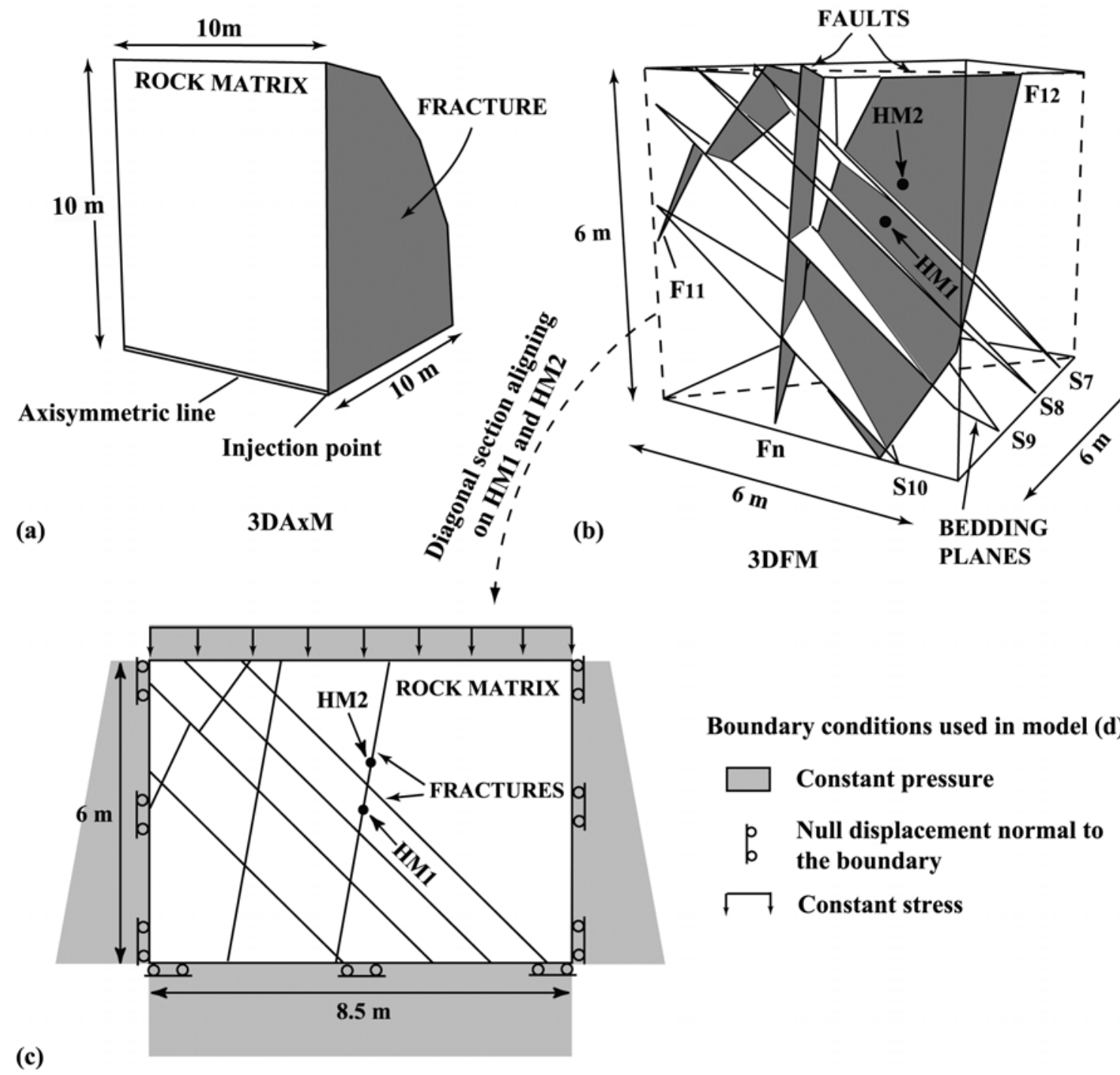

Fig. 7 


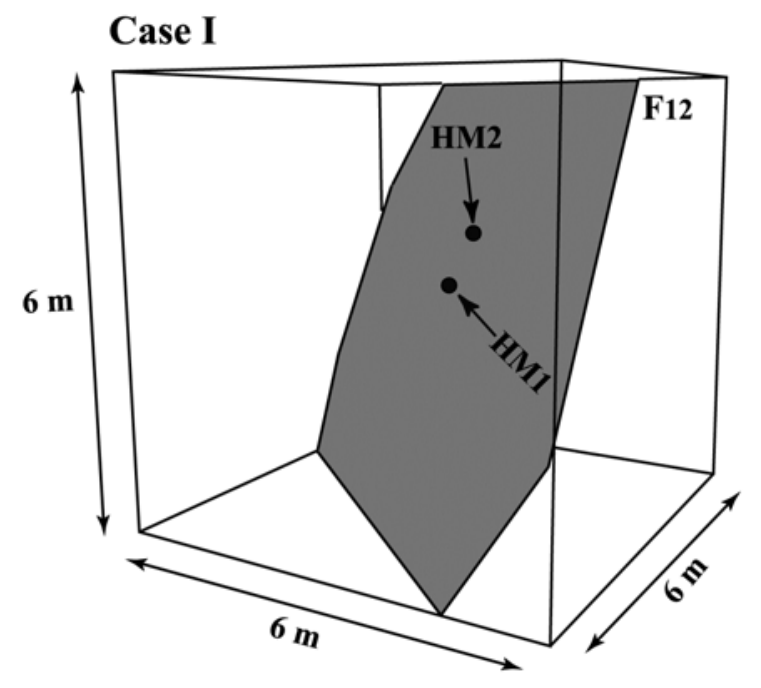

\section{Case II}

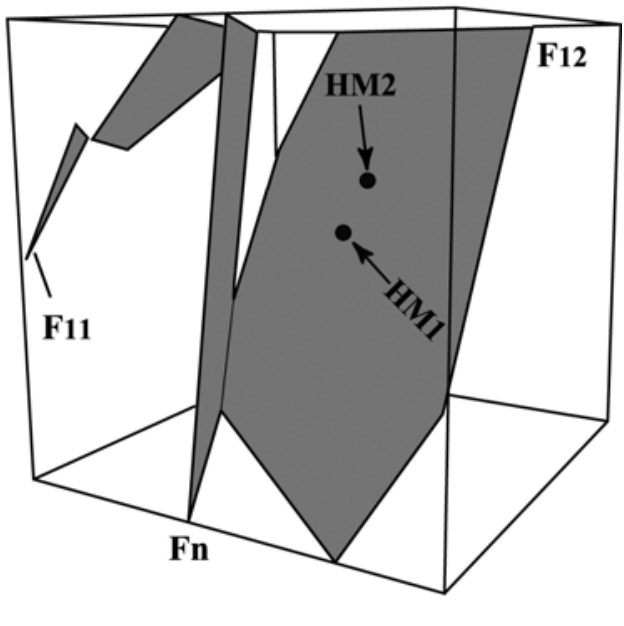

\section{Case III}

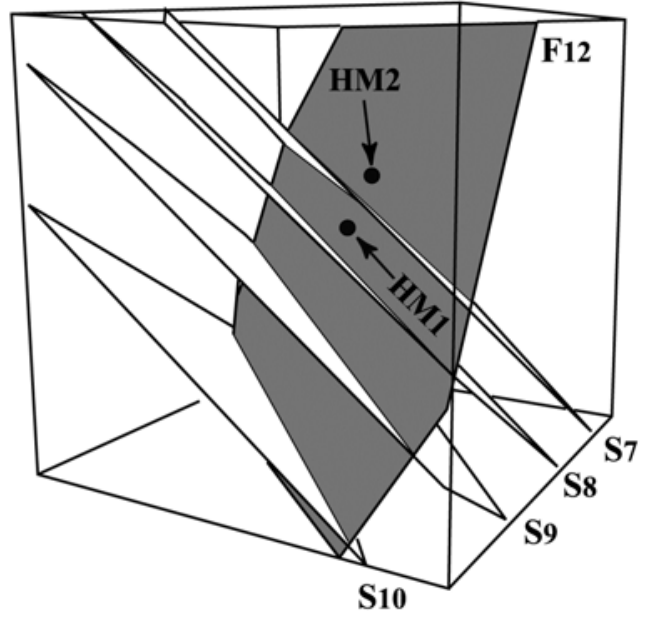

Fig. 8 

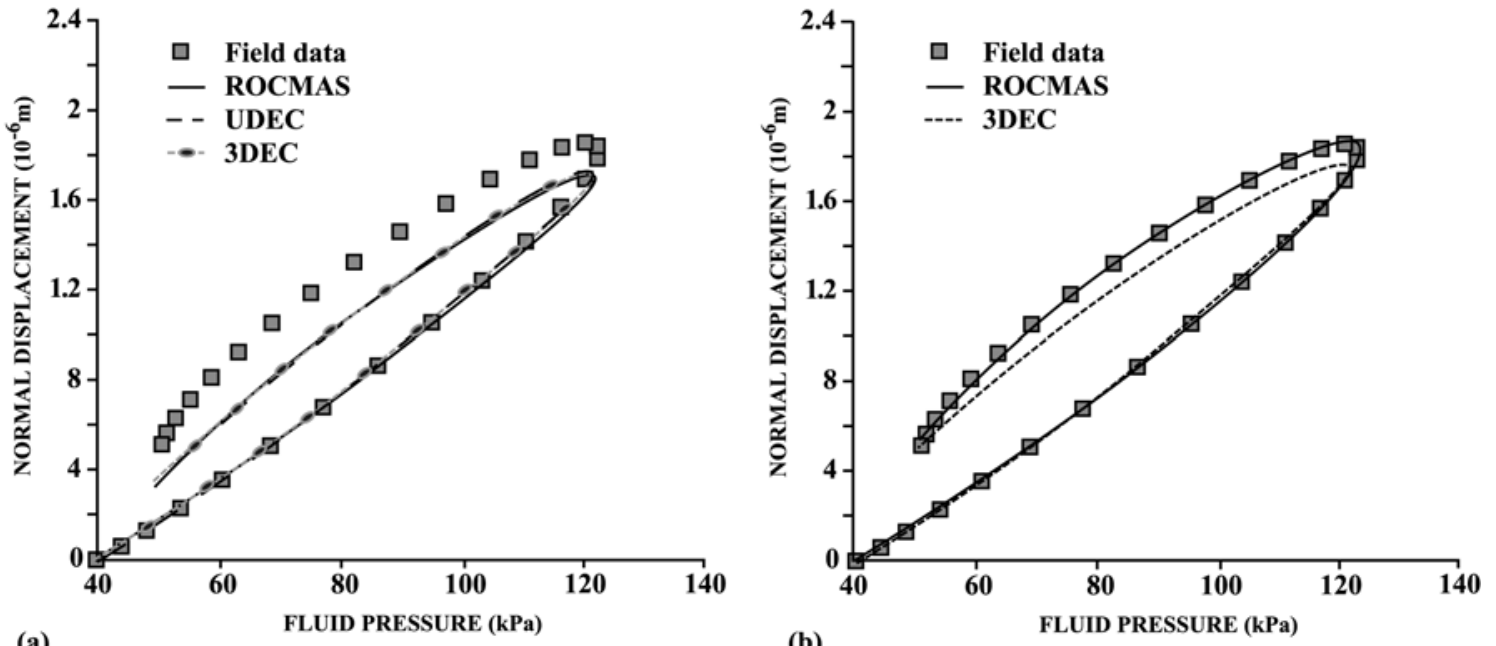

Fig. 9 

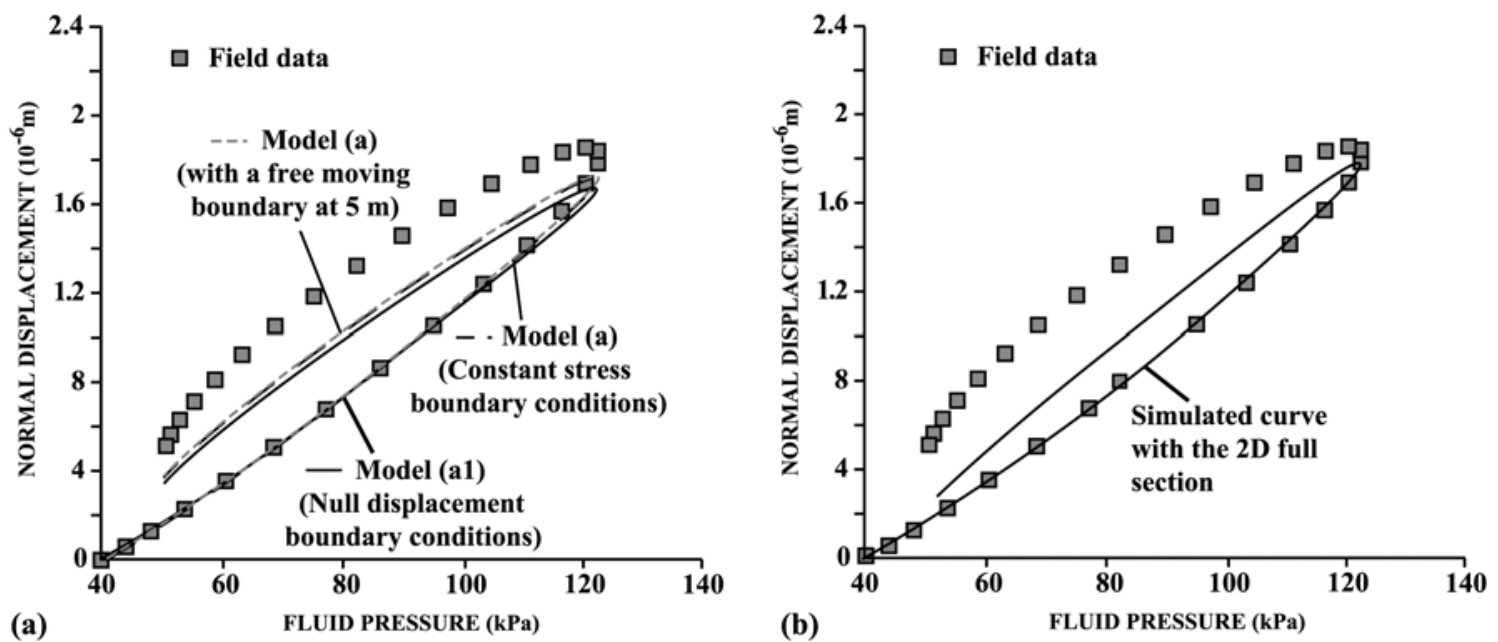

Fig. 10 


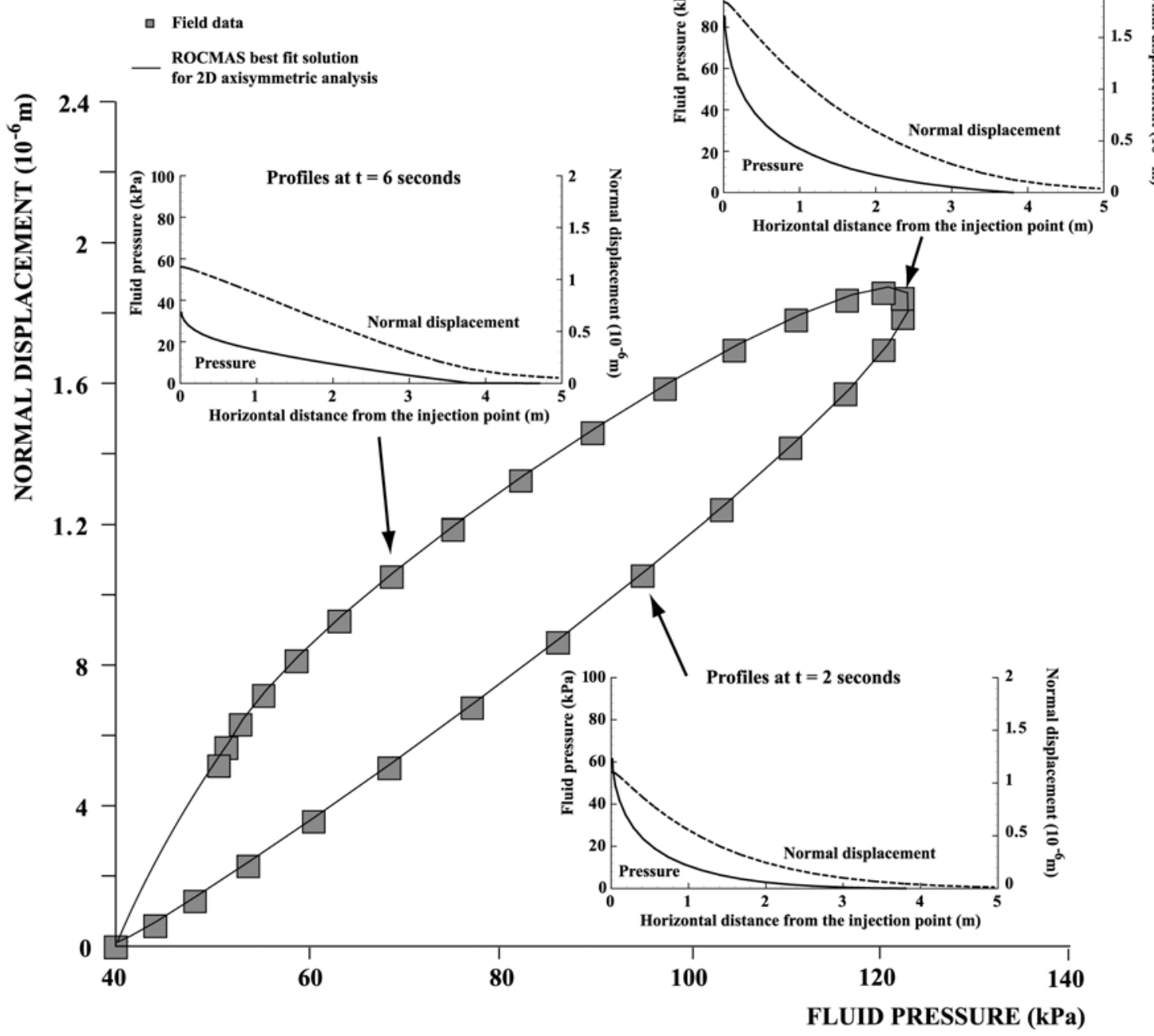

Fig. 11 

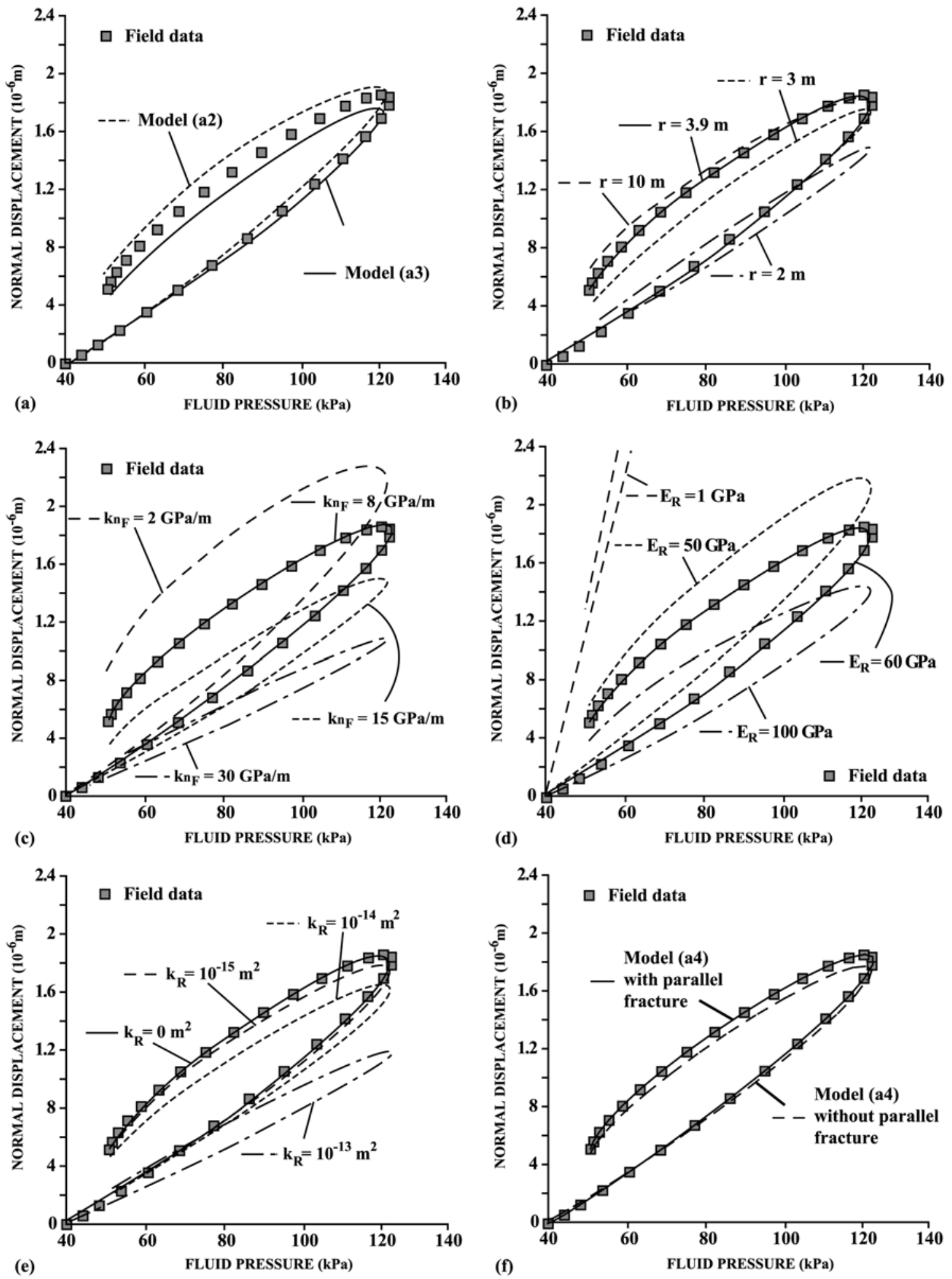

Fig. 12 

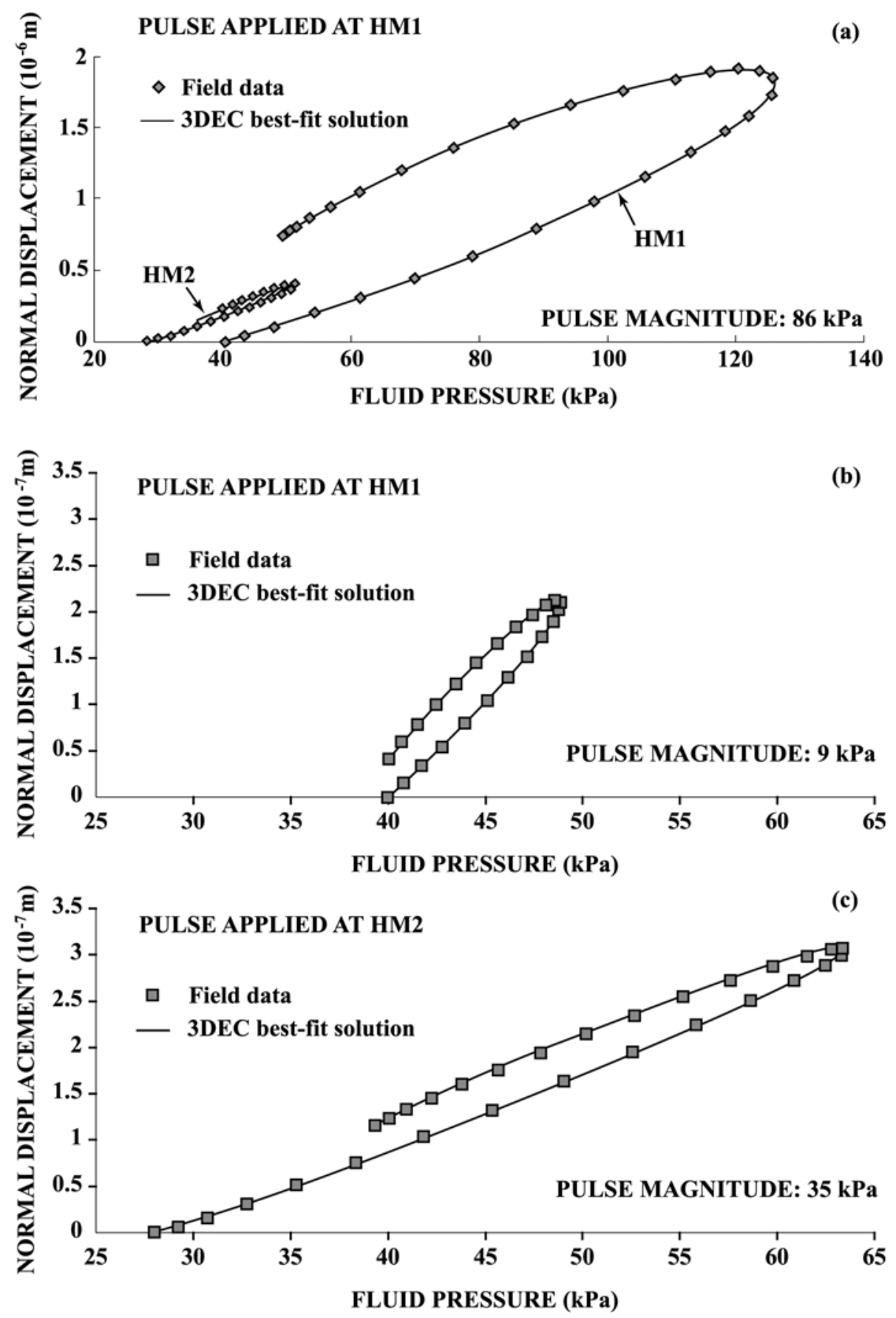

Fig. 13 


\section{PULSE PRESSURE INCREASE STAGE}
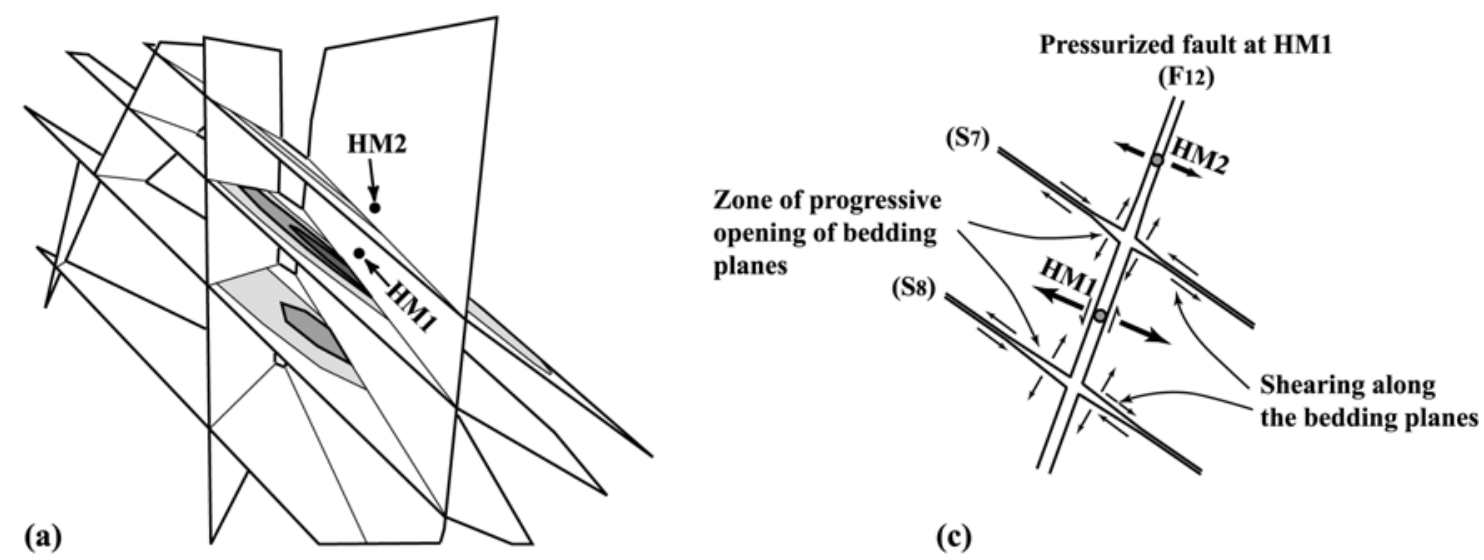

(c)

PULSE PRESSURE DECREASE STAGE
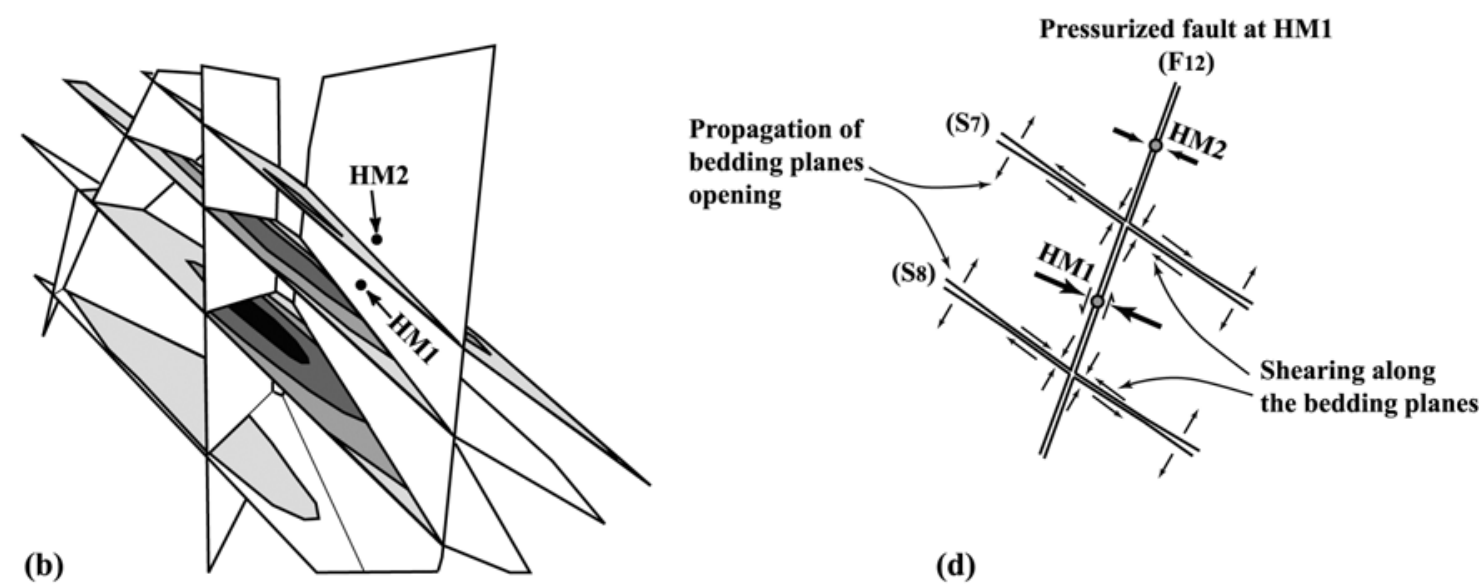

(d)

Magnitude of shear displacements

$\square \times 10^{-7}$ to $5.5 \times 10^{-7} \mathrm{~m} \square 4 \times 10^{-7}$ to $2.5 \times 10^{-7} \mathrm{~m} \square 1 \times 10^{-7}$ to $-5 \times 10^{-8} \mathrm{~m}$
$\square 5.5 \times 10^{-7}$ to $4 \times 10^{-7} \mathrm{~m} \square 2.5 \times 10^{-7}$ to $1 \times 10^{-7} \mathrm{~m}$

Fig. 14 

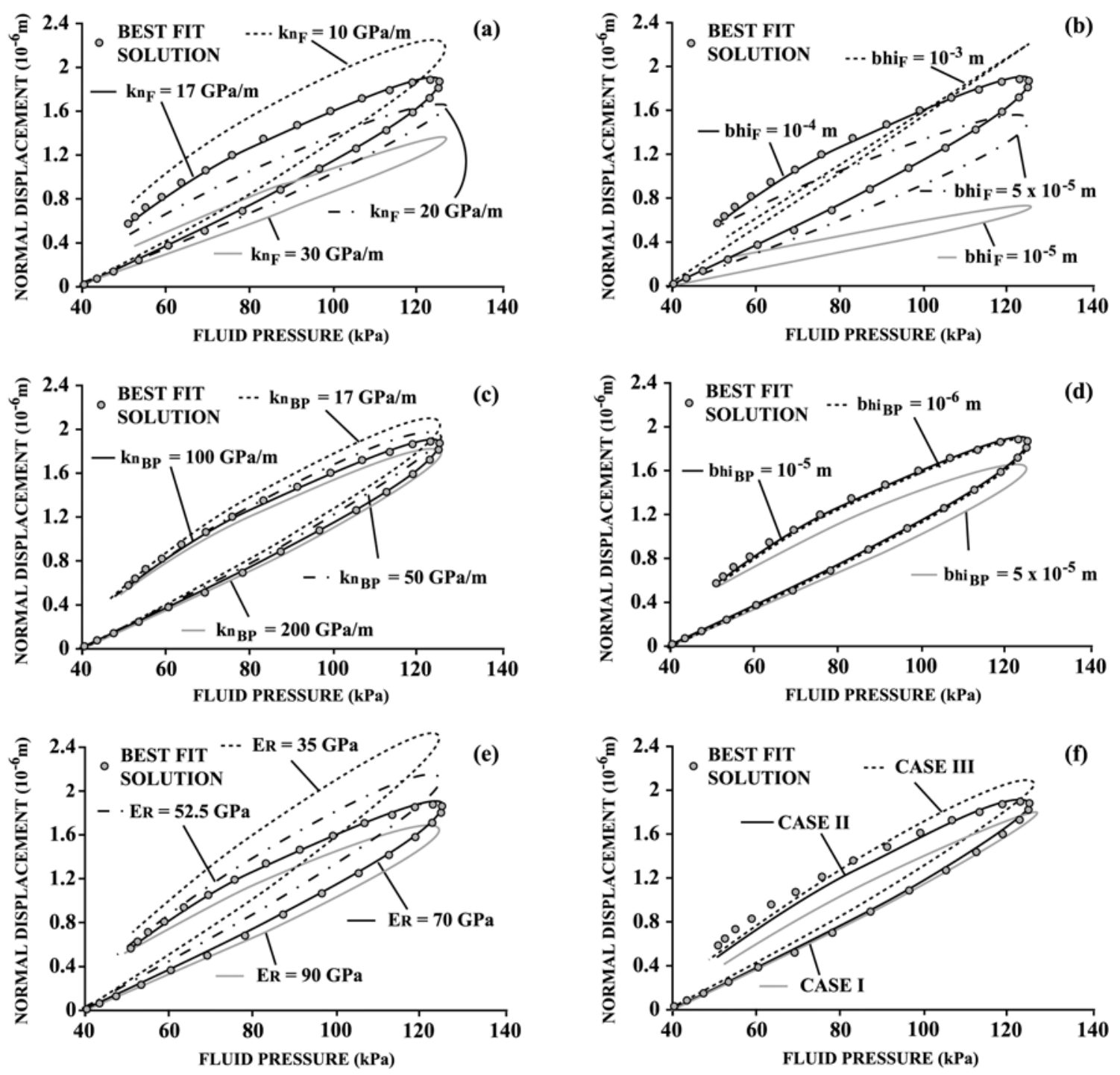

Fig. 15 



Fig. 16 
Table 1.

\begin{tabular}{|c|c|c|c|c|}
\hline $\begin{array}{l}\text { Numerical } \\
\text { analysis }\end{array}$ & 2D Axisymmetric & 2D Plane Strain & 3D Axisymmetric & $\begin{array}{l}\text { 3D Fractures } \\
\text { Network }\end{array}$ \\
\hline $\begin{array}{l}\text { Numerical } \\
\text { Simulator }\end{array}$ & ROCMAS & UDEC / ROCMAS & 3DEC / ROCMAS & $3 \mathrm{DEC}$ \\
\hline $\begin{array}{l}\text { Numerical } \\
\text { model }\end{array}$ & $\begin{array}{l}\text { - } 2 \mathrm{DAxM}_{1} \\
\text { - } 2 \mathrm{DAxM}_{2} \\
\text { - } 2 \mathrm{DAxM}_{3} \\
\text { - } 2 \mathrm{DAxM}_{4} \\
\text { - } 2 \mathrm{DAxM}_{5}\end{array}$ & $\begin{array}{l}\text { - } 2 \mathrm{DAxM}_{1} \\
\text { - } 2 \mathrm{DAxM} \mathrm{M}_{2} \\
\text { - } \mathrm{CSM}\end{array}$ & - 3DAxM & $\begin{array}{l}\text { - 3DFM } \\
\text { - CASE I } \\
\text { - CASE II } \\
\text { - CASE III }\end{array}$ \\
\hline $\begin{array}{l}\text { Parameters } \\
\text { tested in the } \\
\text { sensitivity } \\
\text { study }\end{array}$ & $\begin{array}{l}\text { - Mechanical } \\
\text { boundary conditions } \\
\text { - Radius of influence } \\
\text { - Fracture normal } \\
\text { stiffness } \\
\text { - Young's modulus } \\
\text { of rock matrix } \\
\text { - Rock matrix permea } \\
\text { - Adjacent parallel fra }\end{array}$ & $\begin{array}{l}\text { - Mechanical } \\
\text { boundary } \\
\text { conditions } \\
\text { - Unsaturated } \\
\text { zone }\end{array}$ & & $\begin{array}{l}\text { - Fracture hydraulic } \\
\text { aperture } \\
\text { - Fracture normal } \\
\text { stiffness } \\
\text { - Young's modulus } \\
\text { of rock matrix } \\
\text { - Geometry of the } \\
\text { fractures network }\end{array}$ \\
\hline
\end{tabular}

Table 2.

\begin{tabular}{llrr}
\hline Material & Parameter & Plane strain & 2D/3D Axisymmetric \\
\hline Fracture & Normal stiffness, $k_{n F}(\mathrm{GPa} / \mathrm{m})$ & 40 & 8 \\
& Shear stiffness, $k_{s F}(\mathrm{GPa} / \mathrm{m})$ & 4 & 0.8 \\
& Hydraulic aperture, $b_{h i F}(\mathrm{~m})$ & $1 \times 10^{-4}$ & $1 \times 10^{-4}$ \\
Rock matrix & Young's modulus, $E_{R}(\mathrm{GPa})$ & 70 & 60 \\
& Poisson's ratio, $v_{R}(-)$ & 0.29 & 0.29 \\
& Mass density, $\rho_{R}\left(\mathrm{~kg} / \mathrm{m}^{3}\right)$ & 2400 & 2400 \\
& Permeability, $k_{R}\left(\mathrm{~m}^{2}\right)$ & 0 & 0 \\
Fluid & Mass density, $\rho_{f}\left(\mathrm{~kg} / \mathrm{m}^{3}\right)$ & 1000 & 1000 \\
& Bulk modulus, $K_{f}(\mathrm{GPa})$ & 2 & 2 \\
& Dynamic viscosity, $\mu_{f}(\mathrm{~Pa} / \mathrm{s})$ & $1 \times 10^{-3}$ & $1 \times 10^{-3}$ \\
\hline
\end{tabular}


Table 3.

\begin{tabular}{llrr}
\hline Material & Parameter & UDEC & ROCMAS \\
\hline Fracture & Normal stiffness, $k_{n F}(\mathrm{GPa} / \mathrm{m})$ & 40 & 40 \\
& Shear stiffness, $k_{s F}(\mathrm{GPa} / \mathrm{m})$ & 4 & 4 \\
& Hydraulic aperture, $b_{h i F}(\mathrm{~m})$ & $1 \times 10^{-4}$ & $1 \times 10^{-4}$ \\
Bedding planes & Normal stiffness, $k_{n F}(\mathrm{GPa} / \mathrm{m})$ & 100 & \\
& Shear stiffness, $k_{s F}(\mathrm{GPa} / \mathrm{m})$ & 10 & ${\text { Not } \text { modeled }^{1}}^{\text {Rock matrix }}$ \\
& Hydraulic aperture, $b_{\text {hiF }}(\mathrm{m})$ & $1 \times 10^{-5}$ & \\
& Young's modulus, $E_{R}(\mathrm{GPa})$ & 70 & $30^{1}$ \\
& Poisson's ratio, $\nu_{R}(-)$ & 0.29 & 0.29 \\
& Mass density, $\rho_{R}\left(\mathrm{~kg} / \mathrm{m}^{3}\right)$ & 2400 & 2400 \\
Fluid & Permeability, $k_{R}\left(\mathrm{~m}^{2}\right)$ & 0 & 0 \\
& Mass density, $\rho_{f}\left(\mathrm{~kg} / \mathrm{m}^{3}\right)$ & 1000 & 1000 \\
& Bulk modulus, $K_{f}(\mathrm{GPa})$ & 2 & 2 \\
\hline
\end{tabular}

${ }^{1}$ ROCMAS Young's modulus is reduced to implicitly account for the effects of compliant bedding planes.

Table 4.

\begin{tabular}{|c|c|c|c|}
\hline Material & Parameter & ROCMAS axisymmetric & $3 \mathrm{DEC}$ \\
\hline $\begin{array}{l}\text { Faults } \\
\text { HM1 } \\
\text { HM2 }\end{array}$ & $\begin{array}{l}\text { Normal stiffness, } k_{n F}(\mathrm{GPa} / \mathrm{m}) \\
\text { Shear stiffness, } k_{s F}(\mathrm{GPa} / \mathrm{m}) \\
\text { Hydraulic aperture, } b_{h i F}(\mathrm{~m}) \\
\text { Normal stiffness, } k_{n F}(\mathrm{GPa} / \mathrm{m}) \\
\text { Shear stiffness, } k_{s F}(\mathrm{GPa} / \mathrm{m}) \\
\text { Hydraulic aperture, } b_{h i F}(\mathrm{~m})\end{array}$ & $\begin{array}{c}8 \\
0.8 \\
1 \times 10^{-4} \\
\\
\text { Not explicitly modeled }\end{array}$ & $\begin{array}{r}17 \\
1.7 \\
1 \times 10^{-4} \\
50 \\
5 \\
5 \times 10^{-5}\end{array}$ \\
\hline Bedding planes & $\begin{array}{l}\text { Normal stiffness, } k_{n B P}(\mathrm{GPa} / \mathrm{m}) \\
\text { Shear stiffness, } k_{s B P}(\mathrm{GPa} / \mathrm{m}) \\
\text { Hydraulic aperture, } b_{h B P}(\mathrm{~m})\end{array}$ & Not explicitly modeled $^{2}$ & $\begin{array}{r}100 \\
10 \\
1 \times 10^{-5}\end{array}$ \\
\hline Rock matrix & $\begin{array}{l}\text { Young's modulus, } E_{R}(\mathrm{GPa}) \\
\text { Poisson's ratio, } v_{R}(-) \\
\text { Mass density, } \rho_{R}\left(\mathrm{~kg} / \mathrm{m}^{3}\right) \\
\text { Permeability, } k_{R}\left(\mathrm{~m}^{2}\right)\end{array}$ & $\begin{array}{r}60 \\
0.29 \\
2400 \\
0\end{array}$ & $\begin{array}{r}70 \\
0.29 \\
2400 \\
0\end{array}$ \\
\hline Fluid & $\begin{array}{l}\text { Mass density, } \rho_{f}\left(\mathrm{~kg} / \mathrm{m}^{3}\right) \\
\text { Bulk modulus, } K_{f}(\mathrm{GPa}) \\
\text { Dynamic viscosity, } \mu_{f}(\mathrm{~Pa} / \mathrm{s})\end{array}$ & $\begin{array}{r}1000 \\
2 \\
1 \times 10^{-3}\end{array}$ & $\begin{array}{r}1000 \\
2 \\
1 \times 10^{-3}\end{array}$ \\
\hline
\end{tabular}

${ }^{1}$ In ROCMAS axisymmetric model, HM2 is not explicitly modeled as a point

${ }^{2}$ ROCMAS Young's modulus should implicitly account for the effects of compliant bedding planes 
Table 5.

\begin{tabular}{|c|c|c|}
\hline $\begin{array}{l}\text { Numerical } \\
\text { analysis }\end{array}$ & Tested parameters & $\begin{array}{l}\text { Influence on the } \\
\text { hydromechanical response }\end{array}$ \\
\hline 2D Axisymmetric & $\begin{array}{l}\text { - Radius of influence }(\mathrm{r}) \\
\text { - Fracture initial normal stiffness }\left(\mathrm{k}_{n F}\right) \\
\text { - Young's modulus of rock matrix }\left(\mathrm{E}_{R}\right) \\
\text { - Rock matrix permeability }\left(\mathrm{k}_{R}\right) \\
\text { - Adjacent parallel fault }\end{array}$ & $\begin{array}{l}\text { - No effects if the distance } \\
\text { between the boundary parallel to } \\
\text { the pressurized fracture and HM1 } \\
\text { is equal or higher than } 5 \mathrm{~m} \\
\text { - No effects if ' } \mathrm{r} \text { ' is equal or } \\
\text { higher than } 3.9 \mathrm{~m} \\
\text { - High } \\
\text { - High } \\
\text { - No effects if ' } \mathrm{k}_{\mathrm{R}} \text { ' is higher than } \\
10^{-15} \mathrm{~m}^{2} \\
\text { - High }\end{array}$ \\
\hline 2D Plane strain & $\begin{array}{l}\text { - Topographic surface } \\
\text { - Unsaturated zone }\end{array}$ & $\begin{array}{l}\text { - No effects } \\
\text { - No effects }\end{array}$ \\
\hline $\begin{array}{l}\text { 3D Fractures } \\
\text { Network }\end{array}$ & $\begin{array}{l}\text { - Fracture initial hydraulic aperture }\left(\mathrm{b}_{h F}\right) \\
\text { - Fracture initial normal stiffness }\left(\mathrm{k}_{n F}\right) \\
\text { - Bedding planes initial hydraulic aperture }\left(\mathrm{b}_{h B P}\right) \\
\text { - Bedding planes initial normal stiffness }\left(\mathrm{k}_{n B P}\right) \\
\text { - Young's modulus of rock matrix }\left(\mathrm{E}_{R}\right) \\
\text { - Geometry of the fractures network }\end{array}$ & $\begin{array}{l}\text { - High } \\
\text { - High } \\
\text { - No effects } \\
\text { - No effects } \\
\text { - High } \\
\text { - High }\end{array}$ \\
\hline
\end{tabular}

